\title{
Laboreal
}

Volume $3 \mathrm{~N}^{\circ} 2$ | 2007

Trabalho infantil

\section{O método na vossa loucura : o sistema na vossa}

\section{segurança}

Método en su locura : sistema en su seguridad

La méthode dans votre folie: le système dans votre sécurité

Method in your madness: system in your safety

\section{Andrew Hale}

\section{(2) OpenEdition}

1 Journals

\section{Edição electrónica}

URL: http://journals.openedition.org/laboreal/12606

DOI: $10.4000 /$ laboreal. 12606

ISSN: 1646-5237

\section{Editora}

Universidade do Porto

Refêrencia eletrónica

Andrew Hale, "O método na vossa loucura : o sistema na vossa segurança », Laboreal [Online], Volume $3 \mathrm{~N}^{0} 2$ | 2007, posto online no dia 01 dezembro 2007, consultado o 10 outubro 2019. URL : http://journals.openedition.org/laboreal/12606 ; DOI : 10.4000/laboreal.12606

Este documento foi criado de forma automática no dia 10 outubro 2019.

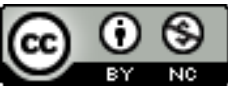

Laboreal está licenciado com uma Licença Creative Commons - Atribuição-NãoComercial 4.0 Internacional. 


\title{
O método na vossa loucura : o sistema na vossa segurança
}

\author{
Método en su locura : sistema en su seguridad \\ La méthode dans votre folie : le système dans votre sécurité \\ Method in your madness : system in your safety
}

Andrew Hale

\section{NOTA DO EDITOR}

Este texto corresponde à transcrição da última aula dada pelo Prof. Hale, a 15 de Setembro de 2006

\section{Introdução}

1 A minha carreira na ciência da segurança deixou-me com duas preocupações constantes. A primeira é a reacção que alguém tem quando ouve que passei toda a minha vida profissional a estudar o risco e a segurança. Depois de um momento de silêncio de espanto e um sorriso nervoso, a reacção é geralmente : "És louco, como podes ter passado 40 anos a estudar isso ? É somente uma questão de pessoas estúpidas que quebram as regras. Não é incrivelmente aborrecido ?" Quando avanço e digo que, antes de mais, sou um psicólogo e que considero isso um grande divertimento e planeio passar pelo menos mais dez anos da minha vida a fazer o mesmo no meu tempo livre, o sorriso torna-se mais fixo e as pessoas começam a recuar para fora da presença deste homem louco. Portanto, um propósito deste discurso é explicar porque tenho sido tão louco ao ponto de dedicar uma vida a estudar a segurança e o que há de tão fascinante neste tema.

2 A loucura também se refere às emoções conflituosas que a segurança, ou melhor, o seu oposto, um acidente sério, fazem surgir. A primeira e mais dolorosa, é o luto sem 
esperança, às vezes tornando-se numa fúria louca que ocorre com a morte ou lesão grave de um membro familiar ou amigo. É para prevenir esta loucura, a dor, o luto e a perda, que a maior parte de nós, no campo da segurança, dedicamos as nossas vidas e todas as nossas capacidades.

3 Mas existe um outro tipo de fúria para a qual a segurança muitas vezes chama à atenção. É a louca frustração com as regras insignificantes, insensatamente forçadas, que estão tantas vezes associadas à segurança. Isto foi caricaturado num programa de comédia recente que vi na televisão Holandesa, no qual uma personagem com a palavra "Arbo" [1] nas suas costas aparecia continuamente a mandar parar qualquer coisa que começasse a ser divertida. Isto dá lugar aos sentimentos de schadenfreude quando as pessoas lêem o tipo de itens de notícia mostrados na figura 1 , onde as nossas preocupações iniciais para com as vítimas se tornam risos ocos, quando vemos quem elas são. A segurança pode levar as pessoas à loucura de muitos modos, e certamente confere-lhes um sentido de humor negro. De modo a manter a loucura e a emoção no seu devido lugar, necessitamos de compreensão e de racionalidade, não em vez da emoção, mas também com ela - mas qual é esse método de manter a loucura controlada?

Figura 1 : BBC News. 21.02.2006 -'http://news.bbc.co.uk/go/pr/fr/-/1/hi/England/Manchester/ 4735984.stm

\section{Manchester: 21 pessoas salvas depois do colapso do piso}
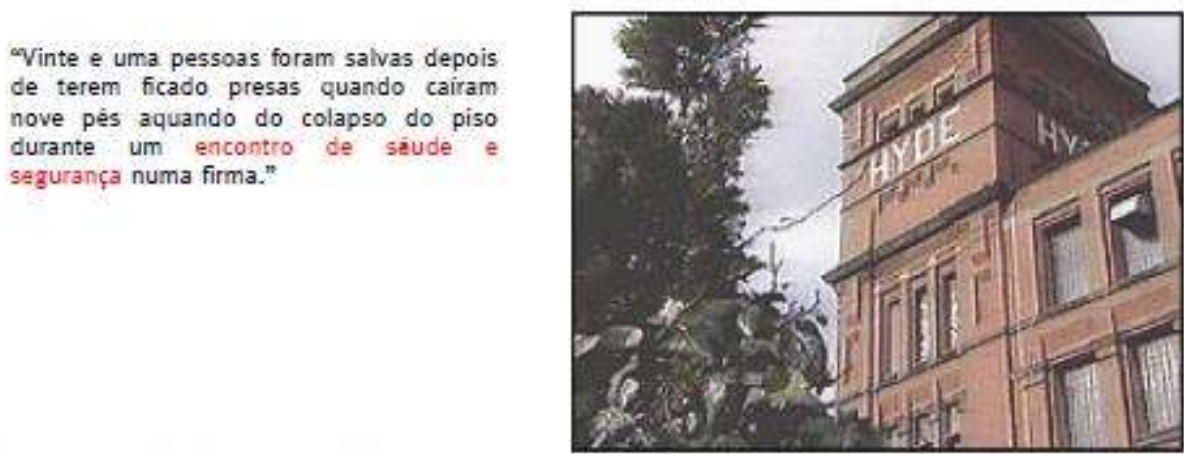

"Vinte e uma pessoas foram salvas depois de terem ficado presas quando caíram nove pés aquando do colapso do piso durante um encontro de sáude e segurança numa firma."

A outra preocupação da minha carreira, e a inspiração para a segunda parte do meu título, tem sido tentar introduzir alguma coerência dentro de algo que alguns podem ter visto como uma colecção caótica de factos e teorias não relacionadas, que fazem a prática da segurança. Ao fazer isto procurei inspiração no complexo de modelos, técnicas e terminologias que recaem sobre a designação de "abordagem de sistemas". Esta procura pela coerência, e pela compreensão de quais são as interacções complexas entre diferentes níveis do sistema e como produzem perigo ou segurança, tem sido uma temática constante nas minhas publicações e é o tema que planeio seguir até a minha reforma. 


\section{Estrutura}

5 Uma aula de despedida é um momento para olhar para trás e um momento para olhar para a frente ; para trás para o que a tua área de estudo atingiu e tu e os teus colegas com ela, e para a frente para o que serão os grandes desafios dos anos futuros, que os teus sucessores terão de enfrentar e superar.

Olhando para trás, podemos perguntar-nos se o mundo é um local melhor com os nossos esforços - no meu caso, é mais seguro ? Sabemos mais acerca de como e porque é ou se torna inseguro e o que podemos fazer acerca disso ? Teremos partilhado o nosso conhecimento com o número suficiente de pessoas certas para fazer algo sobre os riscos que tão assiduamente estudámos ? Escolhi olhar para trás, baseando-me em parte nas tendências do número de acidentes, particularmente no Reino Unido e nos Países Baixos, onde tenho trabalhado. Afinal, uma redução nos acidentes e doenças causadas pelo nosso uso da tecnologia é o que importa na gestão de riscos. Mas as estatísticas podem apenas revelar padrões globais, sendo sujeitas a muitos embargos devido à sua abrangência e à sua fiabilidade (que não irei aprofundar aqui por falta de espaço) e são, essencialmente, muito aborrecidas. Então, como editor de longa data da revista Safety Science, recorri também a uma análise do que o campo da ciência da segurança tem publicado nas suas revistas desde o período em que estas existem, aproximadamente há 35 anos. Foi em 1969 que revistas científicas peritadas com as palavras "acidente" "segurança" ou "risco" nos seus títulos, primeiro nos EUA e depois na Europa. Estudei as 8 seguintes revistas de língua inglesa, que eram disponíveis electronicamente ou em papel na biblioteca da TU Delft [2], desde as suas primeiras publicações :

- Accident Analysis \& Prevention (1969)

- Journal of Safety Research (1969)

- Journal of Hazardous Materials (1975)

- Safety Science, previamente Journal of Occupational Accidents (1976)

- Journal of Loss Prevention in the Process Industries (1988)

- International Journal of Occupational Safety \& Ergonomics (1995)

- Reliability Engineering \& System Safety (1998) [3]

- Policy \& Practice in Health \& Safety, previamente Journal of the Institution of Occupational Safety \& Health (1997)

- Journal of Risk Research (1998)

7 Para cada artigo publicado codifiquei o país de origem do primeiro autor, a actividade ou área de risco pesquisada (indústria, modo de transporte, desporto, lar, lazer, etc.) e o tópico do artigo (análise de risco, modelação, formação, factores comportamentais, design de máquinas, etc.). Estes dados podem dizernos globalmente que progressos têm sido feitos no nosso campo e o que é considerado importante estudar; e podemos confrontar estas informações com os dados dos acidentes. Ao longo do percurso quero indicar de modo breve o que eu penso ser a contribuição que fizémos para este progresso em duas instituições académicas nas quais servi durante a maior parte da minha vida profissional, as Universidades de Aston e Delft.

Olhar para a frente é sempre muito mais difícil. A bola de cristal é ainda uma peça não comprovada da tecnologia. Contudo, passarei o restante do tempo olhando para essa bola de cristal e darei pelo menos, a minha visão pessoal do que o campo deverá fazer, baseado nas áreas em que temos trabalhado nessas duas instituições. 


\section{É mais seguro agora?}

9 A figura 2 mostra dados do RU sobre o número absoluto de mortes, baseado em estatísticas apresentadas numa série de relatórios legais no período de um século.

Figura 2. Número de pessoas que morreram em acidentes registados sob vários Actos no RU 1880-1980 (cortesia da Health \& Safety Executive Statistics Branch \& the COSAS database)

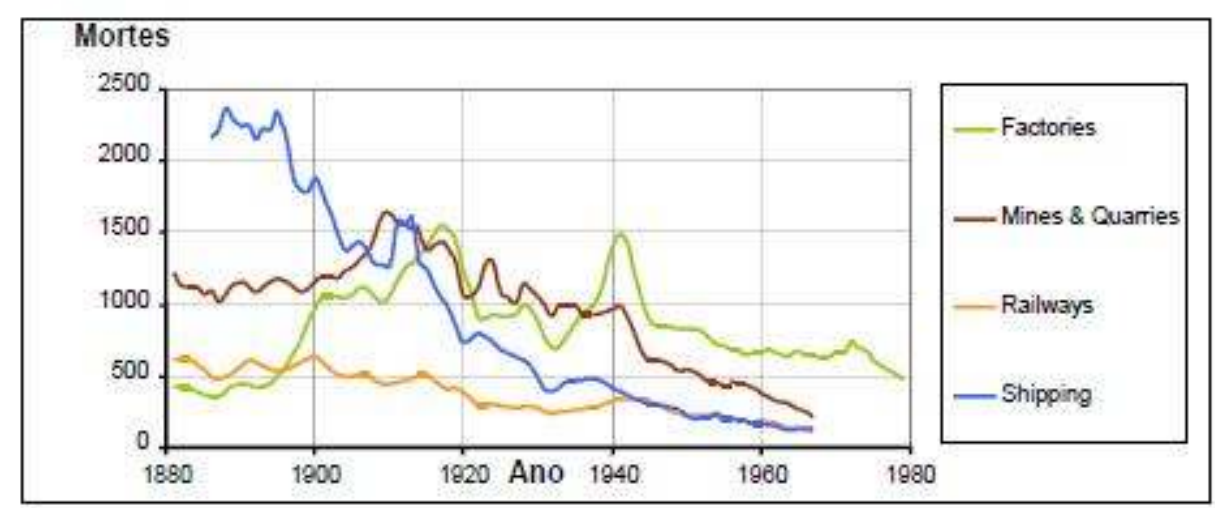

A figura 3 coloca uma lupa sobre os anos decorridos desde 1966 empregados e trabalhadores por conta própria no RU. É Difícil, senão impossível, desenhar uma figura similar sobre um período similar para os Países Baixos, porque o sistema de registo e as definições usadas mudaram drástica e frequentemente durante esses 40 anos (Venema et al., 2006) [ $\left.{ }^{4}\right]$.

Figura 3. Lesões fatais registadas a todas as autoridades por indústria no RU 1966-2004/5 (dados da cortesia da Health \& Safety Executive Statistics Branch \& the COSAS database)

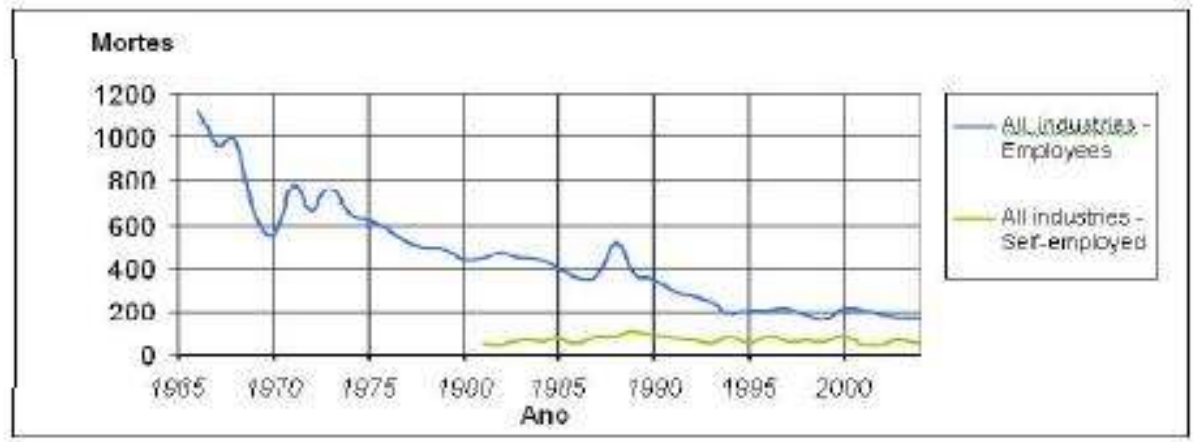

11 A figura 4 indica as mortes rodoviárias no RU e nos Países Baixos, mas desta vez com uma medida por 100,000 da população, de forma a poder mostrar os dois de modo mais comparável. Visto que o uso das estradas aumentou muito no mesmo período, também incluí o gráfico dos quilómetros conduzidos por pessoa, para mostrar que os padrões descendentes nos acidentes são ainda mais significativos considerando o aumento constante de exposição aos riscos da estrada. 
Figura 4. Mortes rodoviárias no RU e Países Baixos per 100,000 habitantes 1950-200. e quilómetros conduzidos por pessoa

(Figuras compiladas do Centraal Bureau voor de Statistiek and Adviesdienst Verkeer en Vervoer e cortesia da Stichting Wetenschappelijk Onderzoek Verkeersveiligheid from the IRTAD database)

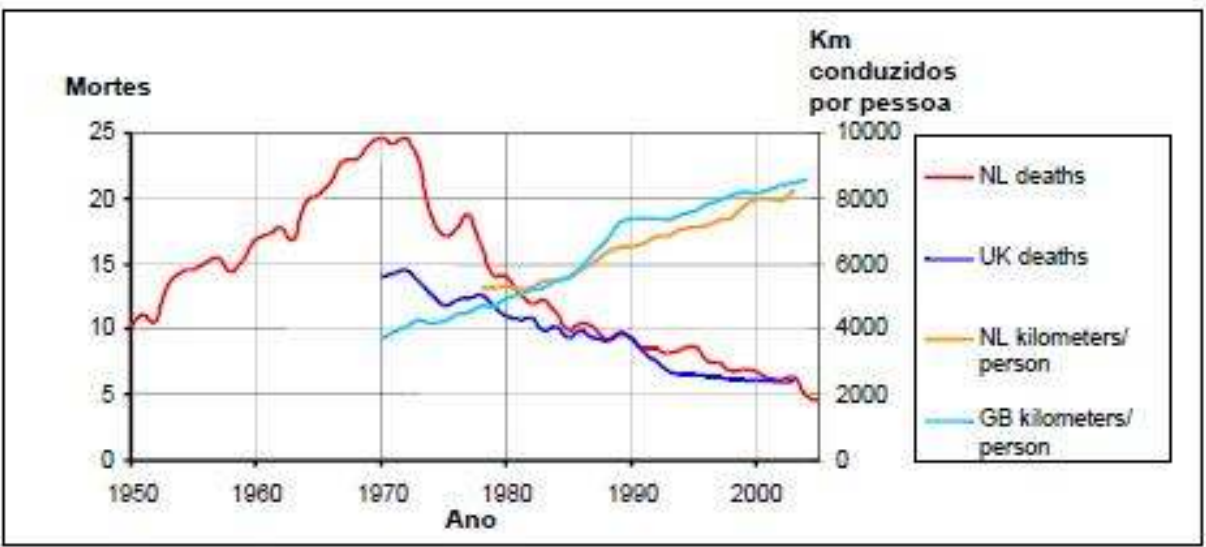

Se olharmos para estas figuras, parece que podemos congratular-nos por um período sustentado de bom trabalho. 0 número de acidentes em todas estas áreas nos países desenvolvidos, e até mundialmente, indica tendências encorajadoramente descendentes durante longos períodos. Existem padrões ascendentes em alguns períodos, alguns dos quais são fruto de mudanças nas exigências dos modos de registo, mas outros (tais como o aumento de acidentes de trabalho na mudança entre o século 19 e 20 e durante a $2^{\mathrm{a}}$ Guerra Mundial, e o aumento de acidentes rodoviários no período pós $2^{\mathrm{a}}$ Guerra Mundial) são causados por aumentos súbitos de exposição a maquinaria ou veículos perigosos, acrescido ao influxo de muitos trabalhadores ou condutores inexperientes. Contudo, a tendência a longo prazo é sempre descendente. Antes de decidirmos que podemos arrumar as malas da ciência da segurança e ir para casa, necessitamos de salientar algumas advertências :

1. Em algumas áreas, tais como a segurança ocupacional e os transportes, precisamos de questionar se a redução ocorreu por causa dos nossos esforços enquanto sociedade para tornar as coisas mais seguras, ou se temos exportado muitos dos riscos, com as indústrias nos quais estes ocorrem, para os países em desenvolvimento. Os números para tais países já são suficientemente horríveis, acrescendo o facto de que são, provavelmente, mais subregistados do que em países desenvolvidos e, de acordo com os dados ILO, os números estão a aumentar, em vez de diminuir. A tabela 1 indica o número estimado de mortes por acidente ocupacional e o risco relativo por 100,000 trabalhadores em diferentes partes do mundo.

2. Só com números tais como os de aviação e das rodovias, onde sabemos que a quantidade de tráfego tem aumentado de modo constante, se não explosivo, no período registado, podemos estar orgulhosos do que foi conseguido em termos de vidas poupadas. Contudo, para as mortes rodoviárias, os números continuam assustadoramente elevados, mesmo nos melhores países. Do mesmo modo, a indústria da aviação considera as suas estatísticas de acidentes demasiado elevadas para a confiança dos passageiros.

3. Se olharmos para grandes desastres não é que a tendência seja significativamente descendente nas indústrias de processos. São estes acidentes graves que orientam os media e os políticos, se não a população em geral, e mantêm os nossos esforços preventivos em acção, bem como, consequentemente, as nossas pesquisas financiadas.

4. Estes números de acidentes, particularmente nas economias e infra-estruturas em desenvolvimento, mas também nos cantos mais escuros das nossas economias mais 
desenvolvidas, onde o trabalho temporário, em part-time ou de emigrantes domina, ainda representa um terrível custo de vida e sofrimento, que nunca poderemos considerar como aceitável. Morrem quase 1000 pessoas em todo o mundo, em acidentes de trabalho, todos os dias de todos os anos e um múltiplo desse número em acidentes rodoviários.

5. Todos os gráficos mostram uma tendência para o equilíbrio ao longo do tempo, indicando a necessidade de intervenções mais inteligentes, mais ideias novas e uma abordagem para a prevenção mais integrada. Nos países desenvolvidos a fruta dos galhos mais baixos já foi colhida e obter mais reduções nos acidentes, se as quisermos, custam mais esforço, tanto na pesquisa como na implementação.

Tabela 1 : Estimativas globais para 1998 do número de mortes no trabalho e valores da sinistralidade per 100,000 trabalhadores em diferentes partes do mundo. (Hämäläinen P. et al 2006)

\begin{tabular}{l|c|c}
\multicolumn{1}{c|}{ Regiōes do Mundo } & $\begin{array}{c}\text { Número estimado } \\
\text { de mortes }\end{array}$ & $\begin{array}{c}\text { Valor da Sinistralidade } \\
\text { (100.000 trabalhadores) }\end{array}$ \\
\hline $\begin{array}{l}\text { Established Market Econo- } \\
\text { mies }\end{array}$ & 16,170 & 4,2 \\
\hline Formerly Socialist Economies & 21,425 & 12,9 \\
\hline India & 48,176 & 11,5 \\
\hline China & 73,615 & 10,5 \\
\hline Other Asia and Islands & 83,048 & 21,5 \\
\hline Sub-Saharan Africa & 54,705 & 21,0 \\
\hline Latin America and the Carib- & 29,594 & 17,2 \\
\hline bean & 18,986 & 18,6 \\
\hline Middle Eastern Crescent & 345,719 & 117,4
\end{tabular}

\section{Sobre o que é que temos pesquisado e escrito e será que isso é importante?}

Uma disciplina académica é sempre julgada pelos seus pares nas publicações em revistas científicas com peritagem. Se isso realmente dá uma imagem completa das conquistas de uma área, é algo que também podemos questionar. 0 campo da segurança é uma disciplina muito aplicada, como todas as de engenharia e gestão. A prova da sua força está no sucesso das mudanças que traz no mundo real e, como em todas as ciências aplicadas, muito do seu trabalho está apenas escrito em artigos de conferências, relatórios de empresas ou governamentais. Tem sido uma das minhas tarefas, enquanto editor da revista Safety Science, tentar persuadir as pessoas que escrevem essa literatura cinzenta a dedicar um tempo extra para fazer, a partir desses documentos, um artigo publicável, e a persuadir gerentes relutantes e advogados de empresas nervosos, a autorizar os pesquisadores e profissionais a publicar resultados, mesmo que (ou talvez especialmente se) estes forem negativos. É uma indicação do status crescente da área de estudo, que eu e os meus colegas editores de revistas sejamos frequentemente inundados com artigos de pessoas que fazem exactamente isto. Devemos aceitar que a publicação em revistas é um indicador útil de uma área de 
estudo e ignorar de momento outros factores possíveis para o aumento de publicações nas revistas, nomeadamente a obtenção de estatuto académico, progressão na carreira e financiamentos proporcionais às publicações, que por este facto escrevem mais e publicam mais, mesmo que não efectuem mais pesquisas.

As figuras 5 e 6 indicam como a globalidade dos números de artigos ao longo dos anos, desde 1969 até 2005, são divididos entre os principais continentes e entre os principais países contribuidores da Europa. Hale, 1972)

Figura 5. Primeiro autor de artigos de revistas (8 revistas) por continente de origem 19692005

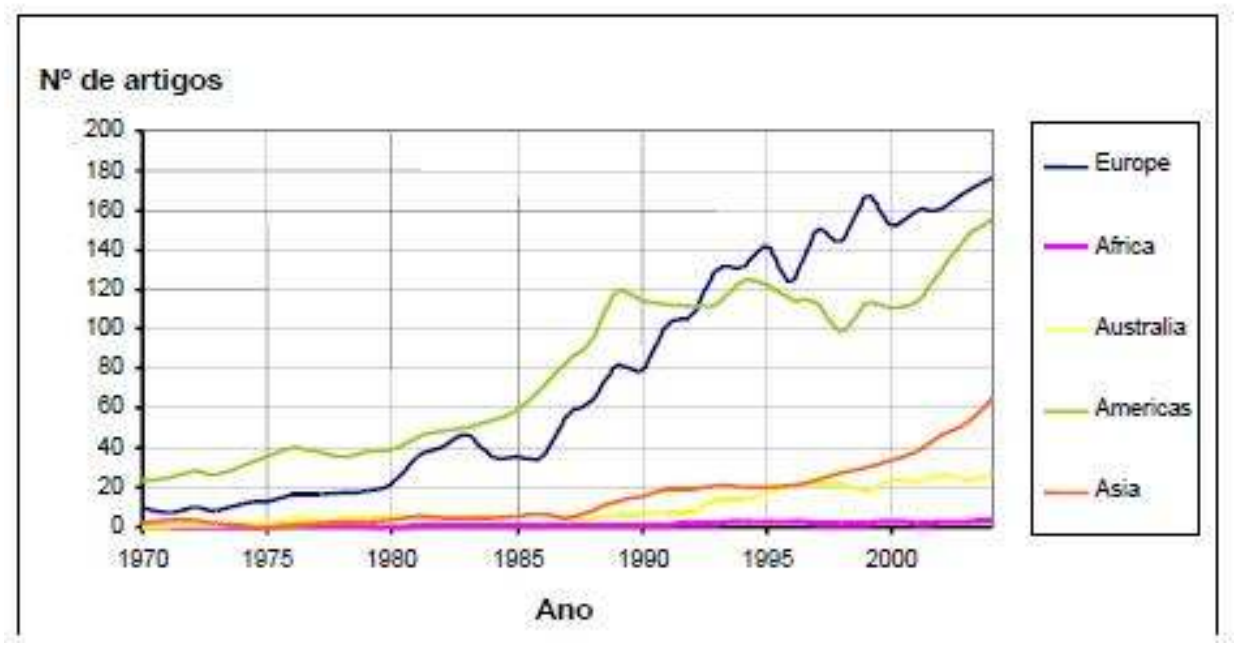

Figura 6.

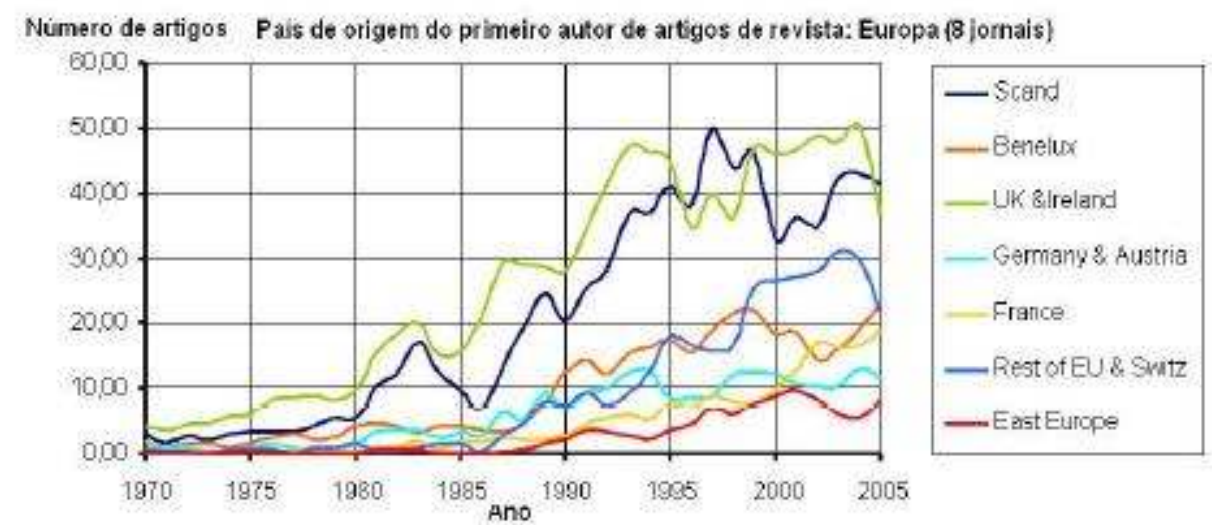

15 Claro que estas são revistas de língua inglesa, dando aos nativos da língua inglesa uma vantagem natural. Isto pode, em parte, explicar o número relativamente baixo de contribuições, até há pouco tempo, de países como a França, Alemanha e Itália, e torna as contribuições dos Países Escandinavos e dos Países Baixos ainda mais impressionantes. Nos últimos dez anos vemos um grande passo adiante para uma quantidade de países da Europa, reflectindo o crescente domínio do Inglês. Notoriamente vemos uma diversificação mundial ao nível dos países que publicam, com forte desenvolvimento em países como a Índia, China, Taiwan, Japão, Coreia, o Médio Oriente e Europa do Leste. Os autores destes países tendem a publicar (para já) maioritariamente sobre assuntos de segurança técnica, mas é claro que, nas décadas 
que virão, irão colocar um selo cada vez mais crescente no desenvolvimento da nossa área de estudo. Se compararmos estes valores com a tabela 1 vemos claramente que as taxas de publicação e de acidentes estão negativamente correlacionadas. Em que consistem as relações causais é uma complexa, mas interessante, questão. 0 que a correlação faz surgir, enquanto questão, é se as despesas em pesquisa são bem direccionadas e se os insights resultantes da pesquisa em economias desenvolvidas são, pelo menos, úteis para o desenvolvimento, ou se têm mais para aprender com o nosso passado do que com o nosso presente.

A tendência mais marcante é, claro, o aumento enorme de artigos publicados sobre segurança, mais que um décuplo em 36 anos. Isto não toma em consideração os artigos com tópicos relacionados com a segurança publicados numa série de outras revistas sem "segurança" no seu título, que ainda são muito comuns. Ninguém mais pode esperar incluir toda a literatura sobre segurança numa única revisão temática como eu fui capaz de fazer numa das minhas primeiras publicações. Naquela altura 365 publicações podiam alegar ser a cobertura completa da literatura de língua Inglesa sobre Acidentes Industriais (Hale \& Hale, 1972)

Figura 7 : Área de aplicação dos artigos das revistas (9 revistas) 1969-2005 e mortes registadas de admissões hospitalares resultantes de acidentes nas mesmas áreas de aplicação nos Países Baixos (figuras para 1992 CBS)

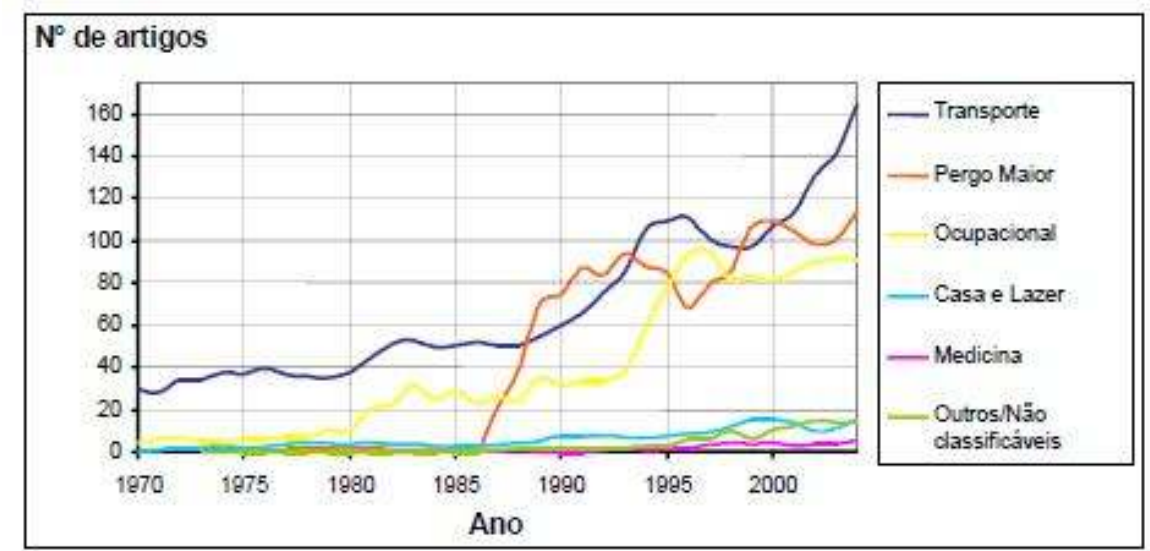

\begin{tabular}{l|c|c}
\multicolumn{1}{c|}{ Tipo de acidente } & Mortes & Admissōes hospitalares \\
\hline Transporte & 1423 & 21,000 \\
\hline Perigo Maior Ocupacional & 43 & 3,000 \\
\hline Casa e Lazer & 2145 & 67,000 \\
\hline Medicina* & 33 &
\end{tabular}

*Estimado na base de estudos dos EUA como ser mais provável de 1.500-3.000 mortes por ano serem resultado de erros em tratamentos hospitalares

Uma divisão vasta da área do risco abordada pelos artigos (figura 7) mostra que são dominantes a segurança rodoviária e o risco nas chamadas maiores indústrias de perigo dentro das indústrias de materiais processados: químicos, energia, óleo e gás. A segurança ocupacional aparece em terceiro lugar, e, outros modos de transporte, segurança do consumidor e do público e os riscos de outros aspectos de vida estão muito abaixo na escala, pelo menos nas revistas analisadas [5]. 0 número de mortes $\mathrm{e}$ hospitalizações nos Países Baixos [ $\left.{ }^{6}\right]$ em cada área estão também indicados na figura. A 
conclusão que parece inevitável é que, aparte dos acidentes rodoviários, as despesas em pesquisa e publicação estão inversamente correlacionadas com o número de acidentes que ocorrem. Podemos colocar a mesma questão aqui, como a mencionada acima, para a distribuição geográfica. Um dos desafios para o futuro é como redireccionar pelo menos alguns dos esforços de pesquisa para as áreas com um maior número de acidentes. Às vezes é dito que não necessitam de pesquisa, visto que são acidentes muito simples. Contudo, o facto de que estes "simples" continuam a ocorrer com grande regularidade é um assunto de pesquisa por si só.

A dimensão final de análise é a do tópico de pesquisa. Aqui agrupei os artigos em vastas categorias da área de estudo, seguindo os níveis num modelo sistemático (figura 8): técnico, humano, organizacional, de sociedade $\left.{ }^{[}\right]$.

Figura 8 : Tópicos de pesquisa de artigos de revistas (8 revistas) 1969-2005

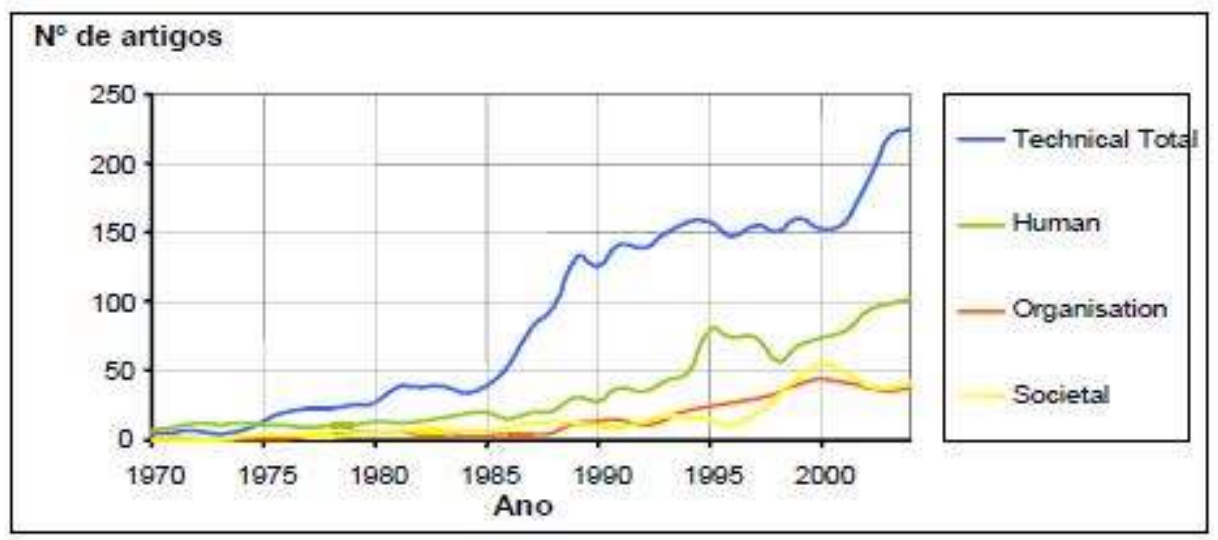

Os tópicos acerca do comportamento técnico e humano são dominantes, com os factores organizacionais a aumentar após o fim de 1980, mas estes ainda estão longe das grandes preocupações de pesquisa, apesar da retórica, minha, entre outros, de que nos movemos, desde os anos 1990, para a terceira idade da segurança (Hale \& Hovden, 1998), com uma concentração na gestão da segurança. Esta pode ser a realidade prática da segurança nas maiores indústrias de perigo e sistemas de transporte, mas a comunidade de pesquisa ainda não fez a mudança. Por outro lado, realizar pesquisas sob influências organizacionais (quanto mais da sociedade) sobre a segurança é um processo muito árduo, dado o grande tamanho, a dinâmica lenta e a intratabilidade da unidade de estudo, comparada com indivíduos ou hard ou software. O que é chocante, a um nível mais detalhado de análise do que o mostrado na figura 8 é que, dos 6058 artigos codificados, existem apenas umas centenas de estudos que avaliam medidas preventivas em qualquer nível do sistema e que estudos em pequenas ou médias empresas são quase inexistentes (21). A pergunta deve ser de novo colocada no confronto entre os esforços de pesquisa e o tamanho do problema do acidente, ou na importância de uma abordagem baseada em factos.

\section{Alguns desafios e conquistas e as suas implicações para o futuro}

20 Agora quero deixar as tendências e números globais e mergulhar em maiores detalhes. Tenho tido o privilégio de trabalhar, e mais tarde liderar, desenvolvimentos na ciência 
da segurança em dois dos maiores centros Europeus de pesquisa e ensino, primeiramente na Universidade de Aston em Birmingham no RU e mais tarde no Delft University of Technology nos Países Baixos. Quero usar as experiências e as conquistas destes dois centros para sublinhar o que já conseguimos atingir, mas também para apontar alguns desafios para o futuro. Farei isso nos dois vastos títulos de ensino e pesquisa.

\section{Ensino}

\section{Sistematizar a segurança}

21 Um dos primeiros marcos no controlo da segurança pela sociedade foi a nomeação dos primeiros quatro inspectores de fábricas no RU em 1833. Foram descritos num discurso de um dos oponentes das reformas da fábrica como :

\footnotetext{
"um advogado sem pasta, um comerciante arruinado, um aristocrata pobre e um amigo íntimo de Lorde Drummond - incompetente para a sua tarefa, mas amplamente providenciado com os meios mais inconstitucionais de irritação e maldade." (Short Time Commitee 1833).
}

Estes homens eram de facto amadores, mas recaiu sobre eles o desenvolvimento da prática profissional da inspecção laboral e o tema da segurança e a regulação resultou das suas experiências em implementar o primeiro efectivo Factories Act de 1833. Durante 140 anos esse conhecimento de como melhorar a segurança pela regulamentação, foi transmitido pela formação no contexto de trabalho.

Em 1972 a colecção variada de pessoal do recentemente criado departamento de higiene e segurança na Universidade de Aston em Birmingham, montado como a primeira unidade universitária de ensino e pesquisa na área de estudo no RU, teve que aprender, no trabalho, a tornar as suas diversas disciplinas básicas num coerente curso de mestrado para os sucessores desses inspectores, quando as formações deles foram outsourced. Consistiam em um engenheiro mecânico experiente em colisões rodoviárias, um psicólogo ocupacional com uma história de investigação em erros humanos e acidentes menores e um físico com um Doutoramento em protectores de ruído e audição, sob a liderança de um médico ocupacional workaholic. Juntaramselhes, mais tarde, um advogado, um toxicologista, um farmacêutico, um historiador, um psicólogo social, um cientista de medicina, um ex-gerente e um engenheiro químico, dando uma noção da amplitude de disciplinas necessárias para leccionar o tema.

24 Esperava-me uma experiência muito similar em Delft em 1984 com uma equipa com um background não menos diversificado, mas mais orientada para a engenharia (aeroespacial, eléctrica, mecânica, de agrícola, química e civil) do que para a saúde ocupacional, mas com um bio-farmacêutico, um técnico de informação e mais tarde nivelado com um conjunto de psicólogos, de diversas variantes como cognitiva, do trabalho e organizacional, sociologia, e ainda mais tarde por mais disciplinas, tais como políticas tecnológicas e engenharia civil.

Tais equipas multidisciplinares têm os ingredientes para estudar e controlar o risco, mas demora um período longo para aprender acerca das abordagens, métodos e skills dos outros e ainda mais para aprender como se integram essas disciplinas em algo coerente que pode ser investigado, praticado e acima de tudo ensinado aos outros. Tem 
existido sempre uma controvérsia sobre se a disciplinas como a ciência da segurança devem ser agrupadas dentro de um grupo organizacional, ou se devem ser desenvolvidas em centros virtuais, onde cada pessoa é emprestada ao centro numa base de projecto conforme os seus skills sejam necessários. A experiência de estabelecer os centros em Aston e Delft convenceu-me de que funciona melhor se as pessoas envolvidas estão a trabalhar para um grupo, podendo dispor do seu tempo e ter completa lealdade. Os que são exteriores ao grupo raramente se integram tão bem. Não existe contacto intensivo suficiente com eles, particularmente nos contactos vitais informais que ocorrem durante o café, almoço e no bar, de modo a desafiar e deitar abaixo as barreiras interdisciplinares e fazer com que ocorra uma integração genuína. A experiência de como são frágeis e vulneráveis às políticas universitárias e à partida de pessoal-chave de tais centros multidisciplinares, foi uma das minhas preocupações acerca da sobrevivência a longo prazo do grupo aqui no Delft. Por isso, particularmente, dá prazer saber que um sucessor forte, o Ben Ale, foi escolhido para continuar o desenvolvimento tanto do grupo nuclear da Safety Science, bem como do centro virtual do Risk Centre que o rodeia, recrutando aqueles que trabalham em várias outras faculdades em tópicos relacionados. Espero que esta combinação permita assegurar o melhor de ambos os mundos.

Projectos de pesquisa integrados podem providenciar a oportunidade para os pesquisadores de diferentes disciplinas aprenderem a combinar as suas teorias, insights e abordagens, mas muito mais eficaz é integrar materiais e cursos de ensino. Os primeiros esforços nesta direcção resultam sempre num ensino desenvolvido puramente da perspectiva de cada disciplina singular, dando blocos de material justapostos, mas não comunicativos. Como próximo passo, os professores individuais moldam as partes da sua disciplina que são as mais relevantes para a segurança e para as necessidades do curso e da disciplina. No meu caso, isso foi a origem do meu primeiro livro (Hale \& Glendon, 1987), mas tais livros ainda permanecem maioritariamente dentro de uma das disciplinas primárias. Só emerge a completa coerência da disciplina se, de algum modo, esta emergir nas mentes dos membros do curso expostos a todo o ensino. Contudo, estes colocam questões aos professores, o que os força a discutir e desvendar a coerência nas versões posteriores do curso. As verdadeiras integrações ocorrem quando os graduados do curso são mantidos como futuros professores. Assim, emergiram os cursos Master e Diplomma em Occupational Safety \& Hygiene no Aston nos anos 1970 e, acrescenta-se a isto, os Masters em Management of Safety, Health \& Envirnoment no Delft no fim dos anos 1980. Depois de 40 anos ainda ocorre o processo de sistematização e eu espero contribuir para isso ainda mais nos anos vindouros, ao registar em formato de livro os frutos de muitas horas de discussão. Central a tal livro, ou talvez uma série de livros, será o preceito de pensamento de sistemas, o que pode providenciar um quadro geral, para unir todos os elementos disciplinares diferentes, num todo coerente.

\section{Desenvolvendo um corpo de praticantes}

Uma área de estudo necessita de um grupo de praticantes de modo a torná-la uma disciplina. Os cursos há pouco mencionados têm sido uma relevante contribuição para desenvolver tal corpo naqueles dois países. Aston formou as mentes de mais de uma geração de inspectores do British Health \& Safety Executives e de muitos profissionais de segurança agora em empregos de segurança séniores. Similarmente, Delft tem 
treinado, através do curso MoSHE e versões mais breves do mesmo para chefes de serviços de segurança e inspectores de óleo e gás, uns 280 profissionais de segurança, particularmente para as maiores indústrias de perigo, mas também para o governo, a defesa, a investigação de acidentes e consultoria. Esta tem sido a bandeira do Safety Science Group através da qual os seus contactos na prática têm decorrido, a qual tem sido alimentada pela sua pesquisa e, por sua vez, tem alimentado aquela pesquisa com novas questões sobre como melhorar a prática. Juntamente com os cursos HVK levados a cabo pelo Stichting PHOV, com os quais tem existido sempre uma troca frutífera de ideias e designs de formação, tem-se produzido um corpo de profissionais a nível sénior agora determinando a política Holandesa, a indústria multinacional e o governo nesta área.

Em paralelo com o desenvolvimento destes cursos tem decorrido um esforço de pesquisa contínuo, de forma a compreender o papel e as necessidades de formação dos profissionais de segurança por todo o cenário internacional. Isto começou com a minha tese de doutoramento sobre o papel e a formação de inspectores de fábricas (Hale, 1978), e continuou através de conferências regulares de cursos universitários sobre a disciplina nos anos 1970, o grupo de trabalho sobre a formação em segurança de saúde do International Social Security Association e profissionais de segurança nos anos 1980 e 1990, e agora nesta década com os European Network of Safety \& Health Professional Organisations. Isto culminou recentemente num estudo importante sobre o que fazem realmente os profissionais de segurança, conduzido em 13 países e ainda a ser analisado (Hale \& Guldenmund, 2006). Isto tem ajudado a alimentar as discussões acerca da harmonização das qualificações por diferentes países e os relacionamentos entre, (e sobreposições com) outras condições e riscos de trabalho, com profissionais tais como os psicólogos ocupacionais, ergónomos, físicos ocupacionais, enfermeiros ocupacionais de saúde e psicólogos de trabalho. Tal pesquisa pode informar e guiar as discussões que têm sido conduzidas durante quase 50 anos sobre possíveis alianças, federações, ou até fusões entre alguns destes grupos. Recentemente, isto atingiu um pico nos Países Baixos, com discussões agora a decorrer entre as três profissões de prevenção mais relevantes, sobre alguma forma de federação que possa sustentar a sua cooperação crescente.

\section{O futuro da educação da segurança}

Tenho pintado uma imagem relativamente cor-de-rosa sobre o desenvolvimento e consolidação de cursos para futuros praticantes nesta área. Mas existe outro grupo, que é igualmente importante, se não ainda mais, nomeadamente os futuros engenheiros, gerentes e outros profissionais cujas decisões determinam se os riscos irão ser tidos em conta no trabalho diário; os graduados das universidades e colégios técnicos de nível superior.

Neste momento pode ser instrutivo desenhar alguns paralelismos entre o desenvolvimento da pesquisa e ensino de segurança numa universidade e o desenvolvimento de um sistema de gestão de segurança numa empresa. No último podemos discernir um número de fases. Primeiro surgem as lutas para o reconhecimento da importância do assunto da segurança. Estas são vistas como lutas para um compromisso, desde o topo da empresa, para gastar recursos, tomar medidas de acção concertadas e colocar a segurança na agenda como um item permanente. Este passo move a empresa daquilo que Westrum (1991) chama de fase patológica para a de 
cálculo. Esta fase é seguida, no estádio 2, por um período de desabrochar, onde existe tanto trabalho para fazer ao estabelecer o sistema para assegurar a segurança, que é nomeado pessoal especializado para fazer a maior parte do trabalho, ou consultores são chamados para analisar os riscos, estabelecer medidas preventivas e monitorizar sistemas. Este é o período do departamento de pessoal significativo, controlado por profissionais de segurança. o lado negro deste cenário pode ser que o resto da organização se encoste para trás e os observe a trabalhar, ou realize apenas o trabalho de produção, que considera muito mais importante. Assim surge o terceiro estádio, a constatação que a segurança tem lugar na linha da empresa, e que todo o pessoal tem uma função na segurança. $O$ departamento de segurança inicia o longo processo de educação da linha e do pessoal, de modo a que fiquem encarregues de todas as tarefas sistemáticas de segurança e de integrá-las com as suas outras tarefas. Isto resulta numa diminuição do tamanho do departamento de segurança, e a sua reforma para uma posição de auditores, ou monitores, e de iniciadores de novas iniciativas de modo a encontrar quaisquer mudanças na tecnologia, organização, regulação ou percepção do risco que podem aparecer no horizonte. Em Delft, e mais cedo em Aston, nós desabrochámos ao desenvolver especialistas para o estádio 2 na indústria, mas agora vamos aplicar os estádios à própria Universidade de Delft e analisar como preenche o seu papel ao incorporar a segurança no seu ensino e pesquisa.

31 Que melhor local para começar do que com as afirmações da política da Universidade. Cito um documento muito recente, "Roads to Innovation", que fornece os planos da universidade para o período de 2005-2008. Sob o "Mission and Vision" na primeira página depois da introdução encontramos isto :

“O TU Delft é uma universidade diversificada e orientada para a sociedade, que pretende oferecer educação e conduzir pesquisas de um nível internacionalmente reconhecido de excelência nas ciências técnicas. Ensino, pesquisa e design estão intimamente interligados com a perspectiva de aplicação na sociedade. O TU Delft trabalha o desenvolvimento da tecnologia para as futuras gerações, desde a base dos valores nucleares da sustentabilidade, segurança e fortalecimento da vitalidade económica."

O que mais poderia querer um profissional de segurança? A segurança é colocada em segundo lugar, mas só atrás da sustentabilidade. Isto não é um problema, dada a extensão e consequências muito superiores da posterior. O que é importante é que vem antes do equivalente educacional da produtividade, que é o local onde sempre a queremos ver - como pré-requisito para a produção. Então parece que temos o apoio do topo da universidade, que é o estádio um.

Este reconhecimento não foi facilmente ganho. Surgiu devido a debates extensivos, dentro do contexto da democratização e abertura ao serviço da sociedade da universidade, que surgiu com furor na França em 1968 e nos Países Baixos durante o fim dos 1970 (Hale \& de Kroes 1997). O Safety Science Group, estabelecido em 1979, foi uma das crianças desta revolução radical, juntamente com os Science Shops (infelizmente na actualidade quase defuntos em todos os locais), e mais significativamente com o refrear dos poderes autocráticos dos professores (também num nível contrário nos anos mais recentes) e o estabelecimento de uma maior democracia universitária. $O$ estabelecimento do Group foi um sinal de que o estádio dois havia sido atingido, com a contratação de especialistas, culminando na minha própria contratação para a disciplina da segurança em 1984. O desabrochar do Group 
desde então e o seu estado saudável como centro lucrativo e relevante, publicador de artigos científicos, líder de um programa de pesquisa ; o Risk Centre da universidade e um programa de pós-graduação de sucesso, para a formação em segurança e especialistas de risco, é uma boa indicação que o estádio dois está a correr bem.

Contudo, se procurarmos os sinais do estádio três, estes não são tão encorajadores. Necessitamos de questionar se a universidade quer realmente dizer o que diz nas suas afirmações políticas e se compromete os recursos para a sua prossecução. Uma busca diligente nas restantes 55 páginas do documento "Roads to Innovation", com todos os seus planos nobres e excitantes, falha em desvendar qualquer uso posterior da palavra "segurança" em qualquer ponto. Temo que aqui, tal como em muitas organizações, ainda exista uma distância entre política e prática, que necessitará da voz alta do “campeão" forte de segurança para suprimir. A segurança não se enraizará nas práticas da universidade, não mais do que o faz numa empresa ou no governo. Ainda necessitamos de profissionais de segurança dedicados na pesquisa, ensino e prática para trabalhar para esse fim, mas acima de tudo, uma liderança comprometida a implementar os seus objectivos de segurança.

Outro sinal de falta de sucesso em penetrar as "line activities" é o destino que tem sempre ocorrido às nossas tentativas para introduzir o ensino em segurança e risco no currículo nuclear das faculdades técnicas. Ao longo dos anos, quase nenhuma iniciativa foi tomada pelo Group para incluir este ensino no material de curso requerido, apesar de ter existido uma colaboração entusiástica por parte do pessoal que ensina naquela faculdade, durante mais de cinco anos. Neste momento, o input do Safety Science Group em tal ensino está com grandes dificuldades. A reforma de campeões internos, a reorganização do currículo e a rejeição dos serviços externos de ensino durante períodos de redução do currículo nuclear matou o ensino, ainda que este fosse altamente valorizado pelos estudantes. Na Engenharia Química, Matemática, Design Industrial e Engenharia Civil existem blocos de ensino que estão preocupados com a segurança e o risco, mas até estes são ainda muito dependentes do compromisso dos professores e prelectores. Isto foi demonstrado como sendo típico em toda a educação superior técnica nos Países Baixos, num estudo que realizamos há 15 anos atrás (Hale et al., 1989), financiado pelo Ministry of Social Affairs, sobre a atenção prestada à segurança nos cursos de educação superiores.

O Delft tomou a iniciativa, no fim de 1990, de assegurar que todas as faculdades incorporavam, nos seus cursos, um elemento obrigatório do estudo da sustentabilidade. Era requerido às faculdades que demonstrassem como tinham implementado este compromisso. Um grupo entusiasta do Technology Assessment Group da nossa faculdade, monitorizou os desenvolvimentos e auxiliou, ao providenciar material de ensino ou fornecendo ensino e supervisão eles próprios. Num certo número de casos, isto teve sucesso ao incorporar aquela disciplina na prática normal das faculdades. Está na altura da universidade fazer o mesmo compromisso, para o termo que coloca em segundo lugar depois da sustentabilidade nos seus valores nucleares. O Risk Centre seria um veículo perfeito para apoiar, monitorizar ou fazer auditoria a este compromisso.

37 As tentativas de persuadir o Dutch Education Ministry a formular um requerimento similar para toda a educação superior Holandesa no despertar do estudo de 1989, em nada resultou, pelo receio de que a política parecesse estar a ser ditada centralmente e, com isso, pisar os calcanhares da liberdade académica. Uma iniciativa a nível europeu 
em 1991 (ISSA 1991) de introduzir a directiva requerendo atenção para a saúde e segurança na educação a todos os níveis, desde a escola até à formação vocacional, também falhou por motivos similares, com complicações destruidoras adicionais, já que o Directorate General responsável pela educação ressentiu-se de uma iniciativa vinda do DG responsável pelo emprego. O projecto ENETOSH, recentemente iniciado na Europa está outra vez a tentar abordar este objectivo, mas num regime de voluntariado (Bollman 2006). Tenhamos esperança de que, se governos nacionais ou europeus não tomarem uma iniciativa, as universidades locais tais como o Delft cumpram as promessas efectuadas nas suas afirmações políticas. Gostaria de desafiar as federações de empregadores e os corpos profissionais para abordar os directores das faculdades e reitores e persuadi-los sobre quão importante é uma compreensão da gestão do risco para o sucesso da estratégia de auto-regulação, que muitos países têm implementado nos últimos 30 anos. Se os designers, gestores e profissionais não compreenderem o risco e como este emerge e pode ser gerido, tal abordagem é um ponto morto. Os empregadores devem declarar os graduados como não empregáveis, se não empregáveis, se não tiverem esta bagagem integrada na sua formação universitária, profissional e técnica.

\section{Temas de pesquisa}

Coloquei ênfase na formação e na educação porque representam o sistema e a estrutura de uma disciplina, mas Delft tem sido, nos últimos 20 anos, mais um local de pesquisa do que de ensino.

Para um conjunto mais ou menos aleatório de contratos de pesquisa de patrocinadores externos, com um pot pourri de tópicos de pesquisa, alguns dos quais foram difíceis de distinguir da consultoria, passámos de uma fase de definição de temas para a focalização de pesquisa (Hale \& de Kroes 1997) para um programa de pesquisa maduro que obteve um 4 numa escala de 5 pela última avaliação em 2003.

Os temas que emergiram em Delft podem ser agrupados sob quatro títulos :

- análise do risco e modelação ;

- gestão, cultura e ensino da segurança ;

- a segurança no processo de design, e

- a regulação da segurança.

O último consiste num desenvolvimento relativamente recente, em colaboração com o programa de pesquisa da faculdade acerca do "Reflection on Technology". O nosso grupo da Delft trabalhou no passado em questões como a mudança da atenção regulatória do hardware para a gestão de sistemas (Kirwan et al., 2002), mas isto não foi uma área de pesquisa relevante. Recebemos um grande impulso recentemente, pela chegada do Ferdinand Mertens como professor no nosso grupo, e remetovos para o seu discurso inaugural para a renovação dos desafios (Mertens 2006). Irei falar dos outros três temas e indicarei alguns pontos a salientar nos mesmos.

\section{Análise do risco e modelação de acidentes}

O desafio do controlo do risco é compreender quais os factores que têm um efeito causal no desempenho da segurança e como as mudanças nos mesmos podem ser priorizadas e implementadas de modo a conseguir o efeito máximo, duradouro. Esta é 
uma área de pesquisa relevante tal como o demonstrado o número de artigos encontrados na minha pesquisa de publicações em ciência da segurança, 1570 em 6058 artigos. Em Delft temos trabalhado em três aspectos principais : como ligar os factores causais por diferentes níveis de sistema; como preencher os modelos qualitativos com números de risco significantes ; como representar a natureza dinâmica da segurança e acidentes.

A história da segurança começa com a preocupação pelas causas proximais da falha tecnológica levando à lesão ou à danificação, movendo-se rapidamente para o papel do humano nas causas proximais dos acidentes (Shaw \& Sichel, 1971) e depois aprende a subir a cadeia causal, recuando no tempo, às causas dentro das organizações, design, regulação, sociedade e cultura. Rasmussen demonstrou esta hierarquia claramente na figura 9.

Figura 9. Modelo de níveis de sistema para o controlo de risco. Adaptado de Rasmussen (1997)

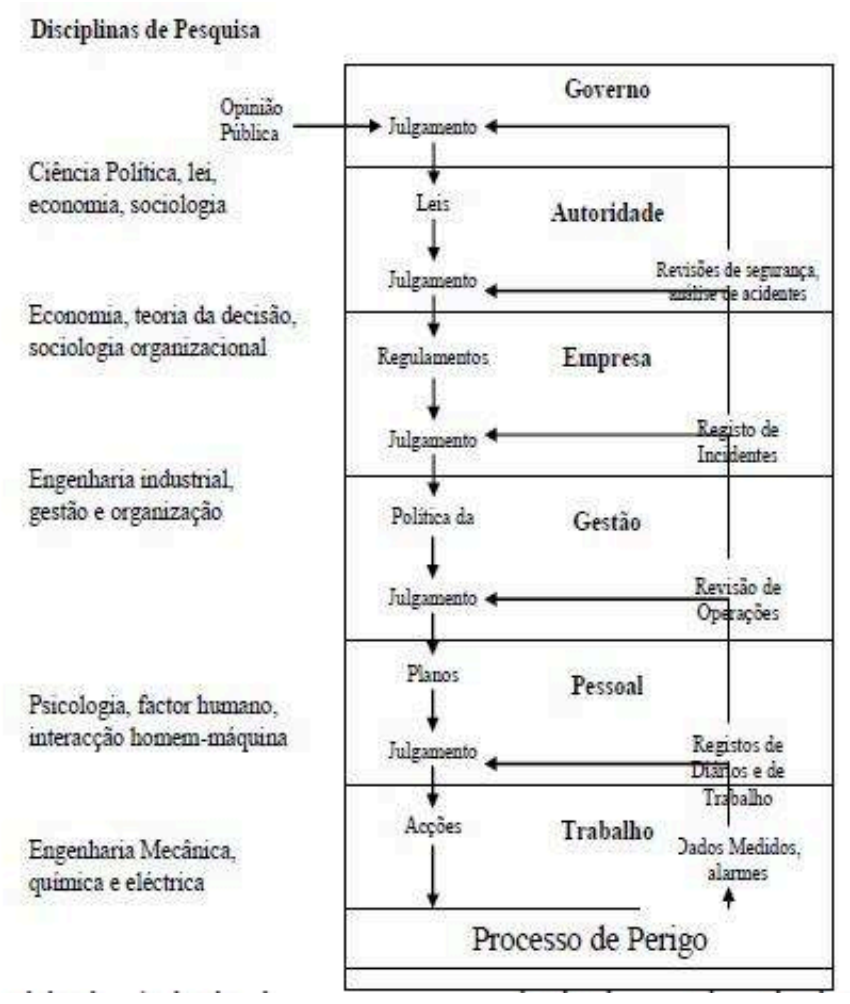

Isto é um reconhecimento que o hardware, acima de todos os humanos, falhará sempre em alguma altura ou de algum modo, e assim não pode ser culpado per se por cometer erros. Os sistemas necessitavam de ser concebidos e geridos de modo a ter isto em conta. Ao investigar qualquer acidente, os pesquisadores necessitam de continuar a questionar as pessoas envolvidas sobre o que e porque fizeram, até chegarem ao ponto de serem capazes de dizer: "Nestas circunstâncias teria feito o mesmo." Só nesse momento é que conseguem realmente dizer que compreenderam os factores técnicos, organizacionais e sociais por detrás das causas proximais do acidente.

Nos últimos vinte anos, temos tentado adicionar os factores de design e organizacionais aos factores técnicos e modelos humanos como factores de acidente, de modo a dar um significado concreto à mudança de política para a concentração em desenvolver e avaliar os sistemas de gestão de segurança. Qualitativamente, isto é agora um problema 
resolvido (ver abaixo sob "gestão de segurança"). o insight mais importante é a necessidade de localizar toda a análise de risco, numa compreensão clara dos processos que o sistema está a tentar operar e gerir (podendo isto ser quer a entrega de sangue nos hospitais, pilotar aviões ou trabalhar com escadotes). Só depois pode compreenderse como os passos mais iniciais no processo criam as condições para acidentes ou exposição mais tarde, e que recursos e controlos são necessários para manter os processos no percurso certo. Contudo, os problemas surgem quando tentamos quantificar as ligações causais de modo a priorizar as acções de gestão. Porque os factores organizacionais têm muitas ligações com as causas humanas e técnicas, violando a exigência básica da análise da árvore das falhas: as causas devem ser independentes em cada parte da árvore. De facto, temos definido a gestão da segurança, talvez perversamente, como a criação de uma causa efectivamente comum, que procura assegurar que todos os factores causais técnicos e humanos operam continuamente no limite mais inferior da taxa de insucesso. Resolver este problema de quantificação é um desafio relevante, que ainda está a ser trabalhado nos projectos correntes sobre acidentes gerais e acidentes de transportes aéreos. De qualquer modo, a quantificação força a clarificação da formulação de assuntos que colocam questões novas e interessantes para a pesquisa, sobre exactamente que aspectos de gestão influenciam que aspectos de risco. Com a ajuda de avaliações de peritos, desenvolvidas sobre dados derivados em aspectos técnicos de risco, estão a ser conseguidos progressos nesta difícil área, em colaboração com o Group de Roger Cooke em Matemática (Goossens et al 2006).

46 A quantificação também nos força a colocar a questão sobre a exposição - quão frequentemente ou durante quanto tempo estava o perigo presente os acidentes possíveis. Sobre a exposição, temos tradicionalmente praticamente nenhuns dados, uma falha que, com a colaboração recente com o Social Affairs and Employment Ministry, está agora a tentar ser suprimida, com a realização de estudos especificamente concebidos para tal (Bloemhoff et al., 2006).

Uma das coisas que temos aprendido com toda esta modelação, é que o controlo da segurança e risco é irredutivelmente complicado. Os gestores séniores que pedem para o sistema de gestão da segurança ser explicado na famosa "folha de papel A4", estão a enganar-se a eles próprios. Isso pode funcionar para uma empresa que emprega cinco funcionários num ambiente de escritório, mas nunca para uma com riscos significativos, ou uma força de trabalho superior a 20. Isso significa que existe um desafio relevante sobre como se pode visualizar o sistema de controlo do risco, de tal modo que possa ser interrogado tanto a nível global como estratégico, e num nível operacional detalhado. Temos experimentado o Structured Analysis and Design Technique (SADT), que oferece uma visão hierárquica de sistemas e as suas transformações, permitindo a alguém desempacotar uma visão genérica de modo a ver mais profundamente o detalhe de cada caixa (Hale et al 1999), mas estas imagens rapidamente se transformaram num conjunto de linhas e setas assemelhando-se a spaghetti enrolado. Este problema ainda será um desafio no futuro.

A natureza dinâmica do controlo da segurança e do risco também permanece um desafio relevante, para o qual ainda estamos num estádio inicial de confrontação. Os nossos modelos de segurança iniciais eram lineares, ou até estáticos. Os perigos eram retratados como energia ou substâncias escapatórias que podíamos conter ou divergir com barreiras, que tinham simplesmente que ser concebidos e colocados no seu devido 
lugar. Fornecidas as regras para o seu uso, vistas como escrita sagrada, a serem obedecidas literalmente, o problema parecia resolvido. A violação das mesmas devia ser atacada, substituindo, disciplinando ou re-treinando o violador. A segurança adquiriu, por causa disto, a imagem de um processo enfadonho, burocrático, de percorrer listas infindáveis, sendo obediente e obsessivo. Contudo, sabemos intelectualmente há muitos anos, que os sistemas são dinâmicos e possuem muito feedback fechado e circular de adaptação, especialmente quando começamos a modelar a influência dos humanos e das organizações. Os engenheiros de controlo, tais como Cownie \& Calderwood, em 1966, avançaram com modelos de segurança com círculos de feedback, demonstrando a adaptação do comportamento baseado na observação da performance em tempos prévios. Wilde trabalhou estas ideias na sua teoria de risco homeostático (Wilde, 1994) e desencadeou uma vaga de protesto e pesquisa ao aclamar que muitas barreiras de hardware introduzidas no sistema simplesmente desencadeiam adaptações comportamentais que, com o tempo, contrariam o efeito esperado na performance da segurança. Talvez a ideia base desta teoria de risco homeostática, que é mais fácil de perceber, seja a da igreja católica no que diz respeito à contracepção: se se disponibilizam preservativos, aumenta-se o risco de relações sexuais. Outros exemplos são a tendência para as novas ou alargadas auto-estradas construídas para aliviar o trânsito, que atraem mais e mais tráfego até também ficarem com muito trânsito, e a tendência dos designers de esticar e expandir cada geração de edifício, ponte ou outra estrutura, até uma delas cair.

Agora, os modelos do comportamento humano em perigo incluem, de modo rotineiro, estes círculos de feedback. Rasmussen (1997) estendeu o conceito para o nível organizacional e desenvolveu hipóteses de forças ao nível da tomada da decisão empresarial, que empurram com remorsos as operações para e através dos limites das regras e engenhos de segurança, montados para manter operações longe de zonas de perigo. Estamos agora a experimentar com modelos, que tentam operacionalizar estas ideias de manter uma actividade dentro de um envelope de operações, de dinâmica variante segura. Os engenhos de controlo de risco tornam-se depois definidos como o hardware e o comportamento, que nos diz onde nos localizamos no envelope de segurança, detectam e corrigem qualquer abordagem que fazemos demasiado próxima dos limites desse mesmo envelope, e detectam e respondem às acções de outros elementos do sistema que movem o limite do envelope de segurança para a nossa posição. Podemos ilustrar isto com imagens tais como a figura 10, mas necessitamos de explorar se isto é só outra metáfora bonita, ou se pode ser transformado numa ferramenta prática que oferece novos insights para as decisões de controlo do risco. 
Figura 10. Envelope de Segurança e comportamento dinâmico (Hale 2006. Cortesia de Ben Ale)

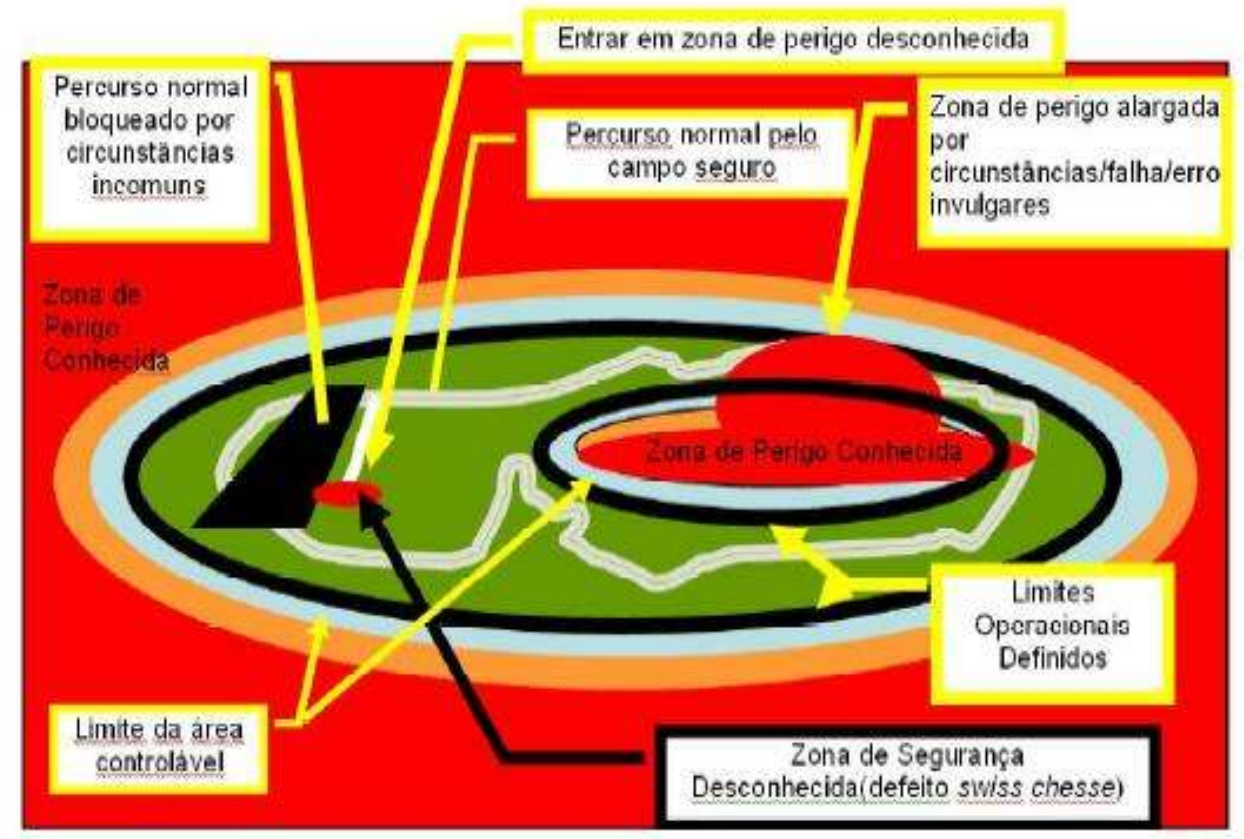

50 Também necessitamos de desenvolver mais ferramentas de modo a antecipar os efeitos de tais forças dinâmicas. Por exemplo, cada conjunto de regras, quer a nível operacional ou a nível das leis e regulamentos nacionais, serão sempre infringidas, violadas, ou usadas criativamente, de modo a atingir os fins dos seguidores das regras, juntamente ou em conflito com os fins intencionados pelos fazedores de regras. Precisamos de uma ferramenta para rever as mesmas, que nos ajuda a prever como e quando isto irá ocorrer, e ainda não a temos. Se pudermos antecipar isto, podemos ter a oportunidade de colocar no seu devido lugar outras medidas para desencorajar a infracção de regras, ou pelo menos monitorizar ou corrigir.

51 Uma implementação completa de tais noções dinâmicas, afastar-nos-ia para longe dos modelos estáticos de risco, actualmente baseados nas árvores de falhas e eventos, que são somente imagens singulares no tempo. Levar-nos-ia para modelos que seriam mais como simuladores de gestão dinâmicos, em que se poderia aprender a guiar sistemas complexos e os seus níveis de risco num nível estratégico.

\section{Sistemas de gestão da segurança, cultura e organizações aprendentes}

A minha pesquisa nos últimos 15 anos tem-se concentrado na gestão da segurança e nos factores organizacionais. Começando pela indústria do aço (Swuste et al., 1994) tem-se alastrado à química, manufacturas gerais e finalmente aos transportes. Os resultados têm-se focado principalmente na clarificação e codificação da estrutura requerida e funcionamento da gestão da segurança e o desenvolvimento de abordagens para a auditoria. Emergiu agora um modelo Delft, baseado também no modelo do círculo fechado, ligando a gestão ao funcionamento das medidas de controlo do risco, que são concebidas nesta figura como barreiras (fig. 11), mas que podem igualmente ser vistas como medidas para manter-te afastado do limite do envelope de segurança. 
Figura 11. Sistema de gestão do controlo do risco (Hale 2003)

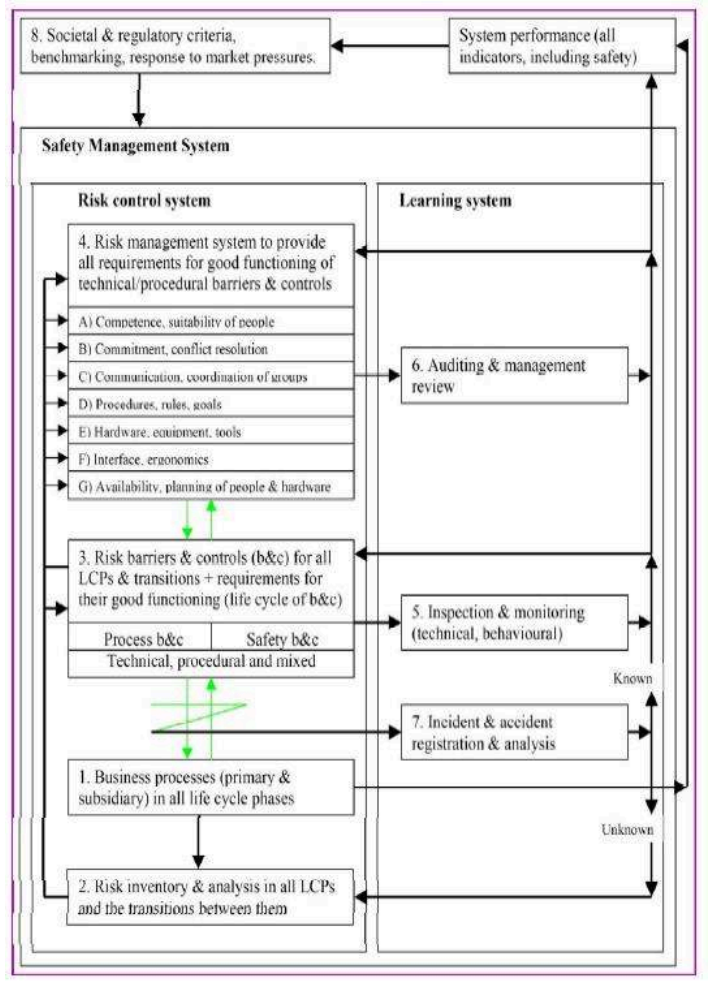

O modelo tem o objectivo de assegurar que as barreiras de segurança críticas, consistindo em combinações de hardware e comportamento, são postas no seu devido lugar e mantidas a funcionar para que cenários de acidente previsíveis ou inimagináveis não ocorram (Guldenmund et al., 2005). Concentra-se em assegurar que o ciclo de vida das medidas de controlo do risco é gerido na sua totalidade, que os recursos e controlos para o fazer são providenciados e que o todo é garantido por uma análise de risco e círculo de aprendizagem, de modo a manter o ajustamento a dinâmica ambiental. Isto encaixa-se no famoso "uma folha de papel A4", mas dá muito pouco detalhe de modo a ser útil, excepto como uma estrutura geral. Cada elemento estrutural na figura 11 está trabalhado para apenas mais um nível de detalhe, como demonstrado no exemplo do procedimento de gestão na figura 12 . 
Figura 12. O Sistema de Regras de Gestão da figura 12 (Hale \& Guldenmund 2004)

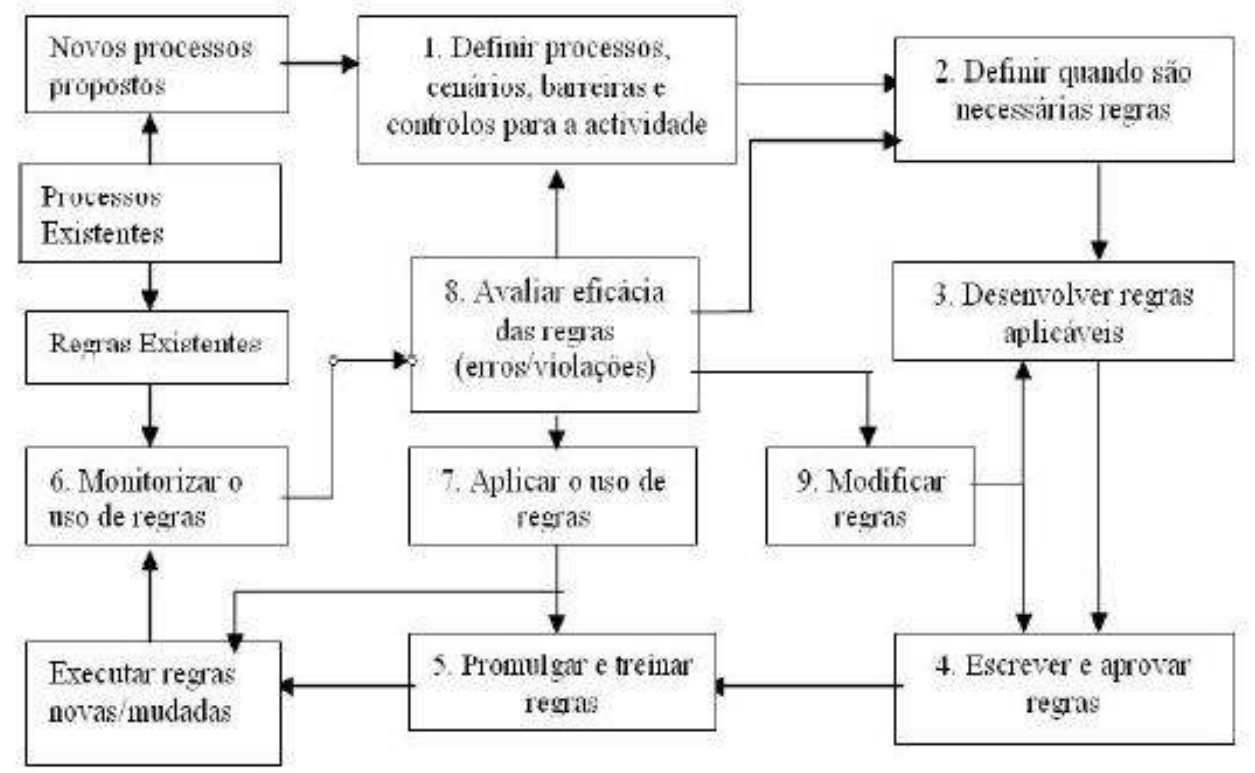

O manual de auditoria que o explica e demonstra como usá-lo ocupa quase 100 páginas. É concebido como um modelo de gestão para sistemas de gestão da segurança bem desenvolvidos, e é fundamentado na ideia de uma auditoria como um processo, enquanto a empresa a quem é feita a auditoria explica como se gere a si própria, de modo a conseguir o relativamente simples conjunto de funções representados pelos blocos nas figuras. Isto é chamado o "scenario-based auditing". Esta noção de auditoria enquanto questionamento socrático e de "story-telling", emparelhado com a avaliação crítica da qualidade das histórias, é fundamentalmente diferente da auditoria baseada numa lista de tarefas muito longa de itens para serem riscados como presentes ou não. Esta noção do "story-telling", é uma que acredito ser vitalmente importante para toda a prática da segurança. Os acidentes tornam-se significativos apenas como histórias e não como estatísticas cruas [8]. Só depois, quando colocadas no contexto, irão mover os decisores para a acção. As histórias estão também cheias de emoção, que é um factor seriamente subestimado na determinação das decisões dos gestores (Rundmo \& Hale 2003).

Precisamos agora de prestar atenção à validação deste modelo de gestão. Uma revisão da literatura de gestão da segurança de há quase 10 anos atrás (Hale \& Havden, 1998), revelou como era escassa a prova científica para a importância dos elementos definidos na maior parte dos documentos de guias e manuais de gestão. Um estudo recente nos EUA (Robson et al., in press), encontrou apenas uma "mão cheia" de estudos que vão de encontro com alguns dos critérios para a validação científica de uma intervenção a nível de gestão, depois de uma primeira filtragem de vários milhares de artigos e relatórios científicos potenciais. Isto é uma área de pesquisa que é difícil de levar a cabo. Antes e depois da ocorrência de estudos de gestão, as intervenções demoram tempo e poucas mudanças são introduções claras de elementos do sistema de gestão individual. Geralmente, muitas coisas mudam de uma só vez ou em sequências sobrepostas, tornando difícil distinguir o que está a ter que efeito. Estudos comparativos de coortes maiores de empresas emparelhadas, com boa ou fraca 
performance de segurança, são dificultadas por problemas em medir a performance da segurança independentemente do SMS (empresas com SMS subdesenvolvidos têm maus sistemas de registo de acidentes e quase acidentes, e podem aparecer melhores que as boas empresas), mas é preocupante como poucas tentativas têm sido feitas de montar tal pesquisa ou de documentar estudos de caso a nível longitudinal em firmas individuais.

Acima de tudo, muita da literatura que existe não aparece em revistas referenciadas, como o número relativamente baixo de 182 artigos durante 21 anos demonstrado no meu estudo. Suspeita-se que não exista um actor influente que tenha um interesse em validar estes sistemas de gestão e de auditoria. Os consultores ainda conseguem vender SMSs sem dificuldade, embora sem qualquer prova de eficácia ; os certificadores fazem muito dinheiro ao conduzir auditorias standard; as empresas compram ou desenvolvem os seus próprios SMS ou sistemas de auditoria com referência "de boca em boca" e não os consideram mais do que expressões lógicas de exigências óbvias que não requerem prova científica. Os governos têm andado tão ocupados a trocar a sua supervisão regulatória pela avaliação do sistema de gestão, de modo a reduzir os números de inspecções e conformar-se com a moda da auto-regulação, que não se têm atrevido a conduzir ou financiar a pesquisa que poderia ter demonstrado que tal avaliação do sistema de gestão não tem valor previsível, em relação à performance da segurança.

Como parte do trabalho acerca da gestão da segurança temos olhado especificamente para as regras de segurança e a sua utilização (e.g. Hale et al., 2003). As regras abarcam os níveis do sistema, desde as regras regulatórias das leis, através de standards, até às regras operatórias no local de trabalho ou na estrada. A segurança não seria possível sem regras, embora os governos e os empregadores venham a argumentar, nos últimos 30 anos, que existem demasiadas. Os nossos estudos indicam que nunca é questionado se as regras de segurança são necessárias, apenas de onde e por quem devem ser concebidas - sendo a resposta o mais perto da prática possível. Se um nível, tal como o governo, elabora menos regras, então, ou um advogado abaixo deve, por sua vez, elaborá-las, ou as regras devem ser passadas aos treinadores e devem estar firmemente implementadas nas cabeças dos utilizadores como parte da gestão de competência. Assim, a auto-regulação necessita de ser acompanhada por mais regras locais e maior esforço de incluir a segurança e o risco em toda a formação técnica, de gestão e profissional. Repito o meu pedido ao governo e empregadores para assegurar que colocam pressão nos estabelecimentos educacionais e de formação, de modo a assegurar que esse objectivo é incorporado em todos esses cursos, como algo com o qual têm que demonstrar a sua colaboração.

Sob este título de sistemas de gestão encontramos novamente os problemas das ligações entre os níveis do sistema e a natureza dinâmica da segurança. A estrutura de um SMS apenas indica o que tem de ser feito e como os processos de gestão devem ser montados de modo a funcionar. Não indica se realmente funcionam e se se entrosam com as partes certas ao nível do hardware e comportamento, de modo a que as medidas de controlo do risco primário sejam escolhidas, instaladas e mantidas a funcionar correctamente, de acordo com a especificação (ou melhor, com as "exigências dinâmicas da mudança"). Uma auditoria tem que penetrar pela papelada e seguir um rasto para a prática das operações. Aqui também encontramos outra área de pesquisa da Delft, aquela do Frank Guldenmund, que agora está a tentar fazer para a cultura e o 
clima de segurança o que fizemos no passado para a estrutura do SMS, nomeadamente para o compreender e defini-lo, medi-lo e demonstrar como se relaciona com a estrutura e o funcionamento do SMS e a sua performance (Guldenmund, 2000). A nossa crítica ao estado do campo no presente é a de que ainda é imatura (apenas publicados 48 artigos no meu estudo, na grande maioria dos últimos dez anos, embora existam muitos mais para o futuro), e existe muito pouca preocupação para com a avaliação se as diferenças na cultura ou clima são reflectidas nas diferenças na performance da segurança, ou nos seus percursores provados.

Finalmente, sob este título encontra-se a questão da aprendizagem organizacional, no qual Floor Koornneef completou o seu doutoramento em 2000. Aí definiu as exigências para um sistema de aprendizagem organizacional eficaz, mas falhou ao não encontrar, nos seus estudos de caso, nem um que fosse de encontro com a maioria dos seus critérios e que poderia ser demonstrado como a trabalhar eficazmente. Agora, ele e os seus outros colegas tomaram a seu cargo o desafio de projectos para desenvolver tais sistemas de aprendizagem, na indústria química, hospitais e até no ambiente mais difícil de design de sistemas de transporte complexos. Parte da mensagem destes projectos de aprendizagem, é paralela àquela oriunda das questões da modelação dinâmica mencionadas na última secção, nomeadamente que a mudança é central, e não a estabilidade, uma noção dura para os praticantes da segurança aceitarem, visto que têm sempre visto a mudança como o inimigo dos sistemas de controlo de risco cuidadosamente estabelecidos. O passo central no design de qualquer conjunto de regras de segurança (ver figura 13) é assim avaliá-las e mudá-las, quando a experiência ou as exigências de mudança as tornam obsoletas. A mudança dinâmica significa vida, 'descanso é ferrugem', como diz o ditado Holandês. Sem tal cuidado, as regras como escritas e as práticas como vividas e trabalhadas desviam-se para longe umas das outras, como o têm demonstrado os estudos de Mathilde Bourrier (1998) na indústria nuclear Francesa, e de Siobhan Corrigan (2002) na indústria de manutenção aérea. As regras são infringidas, com o consentimento de todos os envolvidos, porque de outra forma a actividade pára, por causa das suas contradições e ineficiências internas. Os atalhos (prática laboral) regem, até que algo de muito mal ocorre, quando os escalões séniores levantam as mãos ao céu com um horror hipócrita, sobre como é que as pessoas podem ser tão desobedientes, com regras tão claramente escritas. Só se expusermos esta violação da rotina e a aceitarmos e gerirmos, é que evitaremos estes escândalos periódicos.

\section{A segurança no design}

60 A área final para esta curta revisão da pesquisa de Delft é a de apoiar os designers na sua tarefa difícil de desenvolver novos equipamentos, sistemas e produtos que sejam tão inerentemente seguros quanto os poderem conceber. Aparte dos projectos brevemente mencionados na última secção, dirigindo-se ao modo como os designers aprendem com a experiência passada, a Delft tem dedicado a sua atenção a um número de assuntos. Um foi inspirado pelo trabalho iniciado na Aston pelo Dennis Else e levado por ele para a Victoria, Austrália e por Abeytunga, outro graduado de doutoramento de Aston para o Canadá, nomeadamente o tópico das bases de dados de soluções. Estes dirigem-se à questão sobre como ajudar os designers de departamentos de hardware e técnicos, fazendo o layout dos locais de trabalho e modificação de equipamento, de 
modo a usar as boas práticas de designs anteriores; como encorajá-los a escolher inerentemente designs mais seguros e como fazê-los olhar para além dos limites estreitos da sua própria indústria ou tecnologia, de modo a identificar princípios de design seguros desenvolvidos noutro local. Para fazer isto eficazmente precisamos de definir as medidas de controlo de risco a um nível funcional, para que possamos comparar medidas diferentes para atingir a mesma função, de diferentes formas. A nossa modelação de segurança, sob o nosso primeiro tema de pesquisa, tem-se alimentado de e alimenta este trabalho. Paul Swuste (1996) completou o seu doutoramento sobre o design de um sistema inteligente que consegue todos estes aspectos. É triste relatar que esse design e o seu software de demonstração ainda definham inutilizados na prateleira da União Europeia, vítima de uma falta de iniciativa por parte da European Agency para introduzi-la e apoiar o seu desenvolvimento e uso ulterior. Isto é particularmente triste, porque os esforços de coleccionar e disseminar a boa prática e conseguir implantá-la não parecem ser muito eficazes. Em muitas áreas, desde a adequação dos diques que protegem Nova Orleães contra o furacão Katrina, até aos modos de prevenção dos acidentes na indústria tal como a construção, ou de design e layout dos locais de trabalho em muitas indústrias dominadas pelos SME, não é que as soluções para os problemas não sejam conhecidas pela nossa disciplina, mas sim que não estejam disponíveis quando são necessárias, quando as pessoas estão a tomar decisões sobre a infra-estrutura, equipamento, locais de trabalho ou medidas de controlo de risco. As últimas reformas do Dutch Working Conditions Law colocam ênfase nos ramos da indústria serem levados a desenvolver os seus próprios catálogos de segurança e soluções de saúde ; esperançosamente pode-se retirar o pó do trabalho anterior feito na Delft, e aplicá-los para os fazer funcionar.

61 Outro ramo de pesquisa tem sido o desenvolvimento de ferramentas que auxiliam o desenvolvimento ou avaliação de novas tecnologias, para melhor ter em consideração as suas implicações de segurança, ou para melhor satisfazer as necessidades e modelos mentais dos seus potenciais utilizadores. Ellen Jagtman (2004) estendeu o uso do método HAZOP para o design das estradas e a tecnologia da informação a bordo do automóvel. Erik Wiersma (Butter \& Wiersma, 2002) tem desenvolvido testes para a avaliação do conhecimento da situação nos controladores de tráfego navais, e Maura Houtenbos (Houtenbos et al., 2004) está agora a terminar um estudo no modo como os motoristas interagem nas junções e cruzamentos e que pistas utilizam para adaptar o seu comportamento entre eles (a natureza dinâmica da segurança regressa aqui como vingança). Jaap v.d. Top está numa fase inicial de pôr todo o seu conhecimento em uso, juntamente com os insights da modelação de risco, ao tentar conduzir o desenvolvimento da nova tecnologia e práticas operatórias nos caminhos-de-ferro, para fazer um uso mais flexível da capacidade, sem sacrificar a segurança [ $\left.{ }^{9}\right]$.

\section{Futuros desafios para a pesquisa}

Quero alargar os meus horizontes nesta última secção da Delft a toda a disciplina da ciência da segurança. Quero olhar para onde estão as fronteiras da nossa pesquisa e sugerir um par de direcções que penso que o progresso deverá seguir, não apenas aqui na Delft, mas a nível internacional. 


\section{Duas faces de Janus}

63 A minha revisão da literatura científica demonstrou que a grande maioria da pesquisa publicada tem sido acerca das indústrias de perigo mais relevantes e os riscos de desastre. Só à segurança rodoviária, das actividades que matam um ou dois participantes em vez de dezenas ou centenas, tem sido dada atenção comparável. Os riscos de perigo mais relevantes e a sua prevenção são complexos e de alta tecnologia o que os torna por sua vez mais atraentes. Requerem métodos e modelos muito sofisticados de modo a compreender as interacções e as situações emergentes que levam ao desastre. Tendem a estar sob o controlo das grandes, visíveis e na maior parte dos casos responsáveis e bem intencionadas empresas, que procuram activamente ajuda dos pesquisadores para sintonizar as suas medidas preventivas, os sistemas de gestão da segurança e as culturas. Isto providencia um paraíso para os pesquisadores, e a Delft tem lucrado daquele clima para fazer a grande maioria do seu trabalho de pesquisa. Também providencia uma vida relativamente fácil para os reguladores, com um alto nível de confiança mútua e um sentimento de camaradagem profissional entre os profissionais e os inspectores da indústria da segurança. É a face sorridente de Janus. A sua face carrancuda é representada por uma proporção de pequenas e médias empresas mal intencionadas e mal equipadas, as indústrias de viela e caseiras, os empreiteiros labour only, os trabalhadores temporários e os países em desenvolvimento para os quais a indústria de risco, poluente e nada saudável é exportada. Nestes, o progresso em melhorar a segurança seria muito mais eficaz em termos de vidas poupadas, mas as empresas estão com falta de pesquisa e de intervenção, se não até num nível patológico ; estão preocupadas com fazer um lucro rápido, ou simplesmente sobreviver num mercado muito competitivo. Os problemas não são compreender os riscos e o que é necessário para controlálos, mas sim espalhar o conhecimento acerca das boas práticas; compreender como ultrapassar as barreiras para a implementação; desvendar e punir o escárnio óbvio das simples regras da prevenção. As relações com os peritos e os inspectores são conflituais e o seu trabalho assemelha-se mais à da polícia do que a um aconselhador amigável. Existe pouco, se não nenhum, apoio para a realização de pesquisas de modo a melhorar a situação, como é demonstrado no meu estudo através do número muito pequeno de estudos de pesquisa publicados nestas áreas. Aqui, a Delft, mas também muitos outros grupos, tem feito pouca contribuição.

Parece-me urgente que tanto o governo como os financiadores de pesquisa reconheçam esta face carrancuda de Janus, dando mais prioridade e adaptando as suas estratégias para a mesma $\left[{ }^{10}\right]$. As abordagens que funcionam para uma face não funcionam para a outra. Pesquisadores tais como o Westrum (1991) têm desenvolvido escalas de maturação da cultura da segurança para representar os passos que vão desde o estado patológico até o sorridente e generativo, mas sabemos pouco ou nada acerca se é possível de facto montar aquela escala, e se for possível, como. Não temos definido se devemos tentar movimentar as empresas de um lado da escala para o outro, ou se seríamos felizes se a maioria das empresas conseguisse chegar a meio do caminho e se tornassem "calculistas". Estudos de pesquisa longitudinais das empresas para realizar tais movimentações e como facilitá-las são desesperadamente necessários. Também somos capazes de precisar de expandir a nossa base disciplinar para fazer isto. Precisaríamos de maior input da sociologia, do direito e da criminologia, antropologia, 
economia e política do que temos agora, na Delft, com a nossa concentração naquela face sorridente de Janus.

\section{Auto-regulação}

65 A divisória entre os bem intencionados e os cowboys também levanta questões de uma natureza fundamental sobre a filosofia da regulação. Os últimos 30 anos têm apregoado a auto-regulação (Robens, 1972), a responsabilidade do criador do risco, a redução da intervenção governamental, a mudança da direcção da regulação da regra para o fim, a inspecção dos sistemas de gestão da segurança e não de porcas e parafusos. Muitos governos têm respondido de acordo, usando isto de modo grato como uma desculpa para diminuir o aparato de governo. Contudo, nem todos têm estado felizes por lhes ter sido dado o fardo da auto-regulação e de fazer as suas próprias regras, particularmente os SME. Pensaram inicialmente que a auto-regulação significaria a desregulação, mas não significa, ou pelo menos não deveria, se nos importarmos com a retenção de uma performance de segurança boa. Os SME muitas vezes pedem regras claras como um modo de reduzir este dever. Isto parece ser paralelo à divisão entre as religiões que enfatizam o livre arbítrio e a responsabilidade pessoal, e aqueles que enfatizam a aderência rígida a um código extenso de regras explícitas. Temos visto de modo cada vez mais claro, nos últimos cinco anos, que estes não se situam confortavelmente lado a lado, como filosofias religiosas numa cultura. É possível implementar ambas as abordagens na regulação da segurança, alocando empresas ou sectores para a autoregulação ou o controlo baseado em regras rígidas, ou deixá-los eles próprios fazer isso, mas criar formas bem definidas de modo a graduar de uma categoria para outra, com testes claros? Isto parece ser um desafio para os reguladores, mas particularmente para os aplicadores. Têm que ser o mais desagradáveis possível para as empresas patológicas e reactivas, de modo a poder fornecer-lhes o incentivo para a graduação de modo a serem, pelo menos, calculistas. Também necessitam de uma ferramenta de auditoria para dizer-lhes quando uma empresa, ou um conjunto de empresas que interagem num sistema complexo, podem ser confiadas à auto-regulação (VACS, 2005). Também é um desafio saber que proporção de empresas podem ser confiadas deste modo - os optimistas dizem a maioria, os pessimistas pensam que é um número muito pequeno.

\section{A imagem global}

Em paralelo com os processos da mudança regulatória traçados acima, tem havido um aumento no out-sourcing, a separação do monopólio das empresas dos caminhos-deferro, telecomunicações e energia e a introdução da competição em mercados onde previamente esta não existia, pelo menos nos mercados nacionais ou locais (de Bruijne, 2006). Uma das vítimas deste processo tem sido o modo como a segurança e a saúde estão a "arranjar-se" naqueles sectores. Em estudos no período anterior à comercialização da certificação dos recipientes de pressão, elevadores e equipamento de elevação (Pietersen et al., 1996) já alertávamos para isto. Temos assistido, de novo, à sua perda nas ferrovias (Larsen et al., 2004), e estudos do sector da aviação Holandesa $(\mathrm{K}+\mathrm{V}, 2005)$ têm demonstrado que ela não existe num grau suficiente para optimizar os esforços da gestão da segurança, ou detectar ameaças para a segurança pela suboptimização dos actores individuais no sistema. Não existe um actor no sistema que 
tenha conhecimento suficiente acerca do que está a ocorrer para ter uma visão global de quão bem ou mal está o sistema, e se algo deve ser mudado. Temos assistido ao mesmo problema nas séries de escândalos da indústria da construção nos Países Baixos nos últimos anos, com ameaças ou até colapsos de edifícios devido a uma falha, ou falta de supervisão do processo de construção, visto que os controladores de construção caros desapareceram, porque foram eliminados da lei. A competição feroz assegura que isto é visto como uma forma de corte de custos sem consequências imediatas - estas vêm depois.

Talvez possamos aplicar os mesmos passos de desenvolvimento que sublinhei acima para o sistema de gestão da segurança, para o sistema regulatório. 0 passo 1 neste caso é a consciencialização de que a legislação é necessária, algo atingido para a segurança ocupacional no século 19 e para outras tecnologias cedo no seu desenvolvimento, quando acidentes espectaculares ocorreram. 0 passo 2 resultou na enorme expansão dos inspectores de segurança especialistas e os regulamentos que aplicam. No passo 3, onde a responsabilidade para a gestão do controlo de risco está para ser delegada para a linha (neste caso para as empresas do governo), precisamos de nos aperceber que a função da segurança (neste caso a inspecção do governo ou ministério) tem que reter um papel de auditoria e monitorização, parte da qual é coleccionar e coordenar a informação da performance das diversas partes do sistema. Quanto mais responsabilidade e controlo é delegado para o sector, maior é a necessidade deste papel de monitorização ser construído e mantido ao nível governamental. Os ministérios têm a responsabilidade de serem agências de aprendizagem para o sistema como um todo; algo pelo que actualmente eles e os seus mestres políticos parecem estar muito desinteressados, se não até de modo antagonista. A integração de muitas organizações, sem uma hierarquia clara, de modo a optimizar a segurança, nos sectores como a ferrovia, energia e aviação, é um dos truques mais difíceis que ocorrem. Sem uma supervisão do governo, e sem aconselhamento independente, corpos de investigação, de revisão e de acidentes para chamar à atenção os intervenientes e o governo quando a supervisão demonstra que estão a falhar, ou a sub-optimizar, não podemos ter ideia se a descentralização está a funcionar, ou o que fazer se suspeitamos que não está.

Uma estratégia que os reguladores parecem estar a tentar, por exemplo nas ferroviárias e na aviação, é de tentar alocar um certo orçamento de risco entre as diferentes organizações que fazem parte de todo o sistema, e pedindo a cada um para provar que continua a manter-se dentro deste valor. Enquanto isto dá um passo em frente para a monitorização que tenho pedido, desencoraja, em vez de encorajar, qualquer esforço colaborativo entre os actores. Encoraja-os a ignorar as interfaces com outros actores dos sistemas, e a optimizar dentro do seu próprio orçamento, mesmo se isto causa problemas extra para os outros. Os cruzamentos de nível tornam-se depois um campo de batalha inter organizacional, sobre de quem são os acidentes que ocorrem, em vez de um desafio conjunto de encontrar uma solução integrada. Uma ideia muito melhor seria do regulador colocar uma obrigação nos partidos dos sectores, de apresentar um caso conjunto sobre como permanecem dentro do critério de risco geral. Isto encorajaria o tipo de discussão estratégica e extensa, sobre como os vários sistemas de gestão da segurança se encaixam, que estudos tais como o de Schiphol $(\mathrm{K}+\mathrm{V}, 2005)$ indicam estar agora em falta. 


\section{A segurança absoluta e a culpa absoluta}

Quero passar agora a uma nota crítica sobre outra base fundamental da nossa filosofia na segurança. É a noção de zero acidentes como um objectivo. Tem sido utilizado como um pedido de divulgação para a campanha nacional de segurança rodoviária na Suécia (Tingvall 2002). Também é o objectivo relatado por muitas empresas de alto risco. Isto parece ser um exemplo luminoso de altruísmo e preocupação para a humanidade, uma noção no mesmo nível que a "maternidade e a tarte de maçã" para a cultura americana. Qual poderia ser a objecção para isso, pelo menos como ideal ? As minhas preocupações são que é, para muitos, demasiado irrealista para ser motivante, mas muito mais fundamentalmente, é que ignora o facto de que a segurança não é uma propriedade independente de um sistema. É sempre conseguido na relação com, e em negociação com outros fins do sistema. Enquanto que em muitas instâncias possa ser possível conseguir melhorias muito consideráveis na segurança, sem prejudicar seriamente qualquer outro fim importante do sistema, no final existirão negociações. Alegar zero acidentes como um fim, nega esses conflitos, ou relega-os como nada importantes na face do zelo missionário do "campeão da segurança". Para mim, isto é o equivalente da segurança aos pedidos dos grupos religiosos fundamentais, subordinando todos os outros fins para a sua única visão do caminho certo para a salvação ou para o paraíso. Zero acidentes é um ideal puro, duro e luminoso - quase que disse "um pelo qual vale a pena morrer". Todo o falatório do risco relativo e do compromisso tresanda a heresia. Contudo, algo negado é algo não pesquisado. Não pode ser tornado explícito, para que possa ser gerido.

70 Também temos que aceitar que algumas das mudanças que surgiram devido a padrões e legislação de segurança mais apertados são indesejáveis no que diz respeito a qualquer um dos partidos ; a crianças em idade escolar são privadas de visitas a quintas locais porque os professores não estão dispostos a aceitar a responsabilidade se acidentes ocorrerem sob a sua supervisão; lares de idosos encerram porque não conseguem pagar as melhorias que vão de encontro aos novos padrões de segurança, e deixam os potenciais residentes nos seus próprios lares, muito mais perigosos ; os inspectores de trabalho requerem encerramentos de linhas nas ferroviárias de modo a proteger os trabalhadores da manutenção nas vias vizinhas, e colocam os passageiros no sistema de estradas significativamente muito mais perigoso ; os sucateiros navais Indianos fazem greve para protestar com a sua perda de emprego, porque o governo Francês decide não lhes enviar o navio da marinha, o Clemenceau, para o demolirem por causa do conteúdo de amianto. Estes são apenas alguns exemplos aleatórios. Precisamos de formas melhores de ver não só os custos do risco, mas também os benefícios, de modo a optimizá-los melhor.

71 Contudo, se aceitarmos o risco e dissermos honestamente a nós próprios que alguns acidentes consequentemente não justificam o custo de evitá-los, temos que enfrentar outro conflito, que correntemente não conseguimos gerir bem. Esse é o conflito entre as percepções do antes e depois de um acidente - a maldição do 20 :20 em retrospectiva. Esta é uma área difícil. As vítimas parecem cada vez mais querer ver rolar a cabeça de alguém quando um acidente ocorre. Isto é importante para eles poderem lidar com a dor e a mágoa de perda e lesão. Os advogados representantes das vítimas querem compensação e punição e procuram um culpado, que com conhecimento tomou uma decisão que levou ao acidente. Os advogados da defesa requerem que os clientes se 
mantenham calados e não admitam nada. A vítima é a abertura requerida para a aprendizagem, como nos demonstrou o caso da acusação de um controlador de tráfego aéreo no Schiphol, depois de um acidente de incursão na pista. Dois controladores foram acusados, em parte com base na informação contida no sistema de registo de incidentes internos da empresa. O resultado foi uma queda na reportagem de problemas potenciais e oportunidades de aprendizagem de mais de $50 \%$, que ainda hoje não recuperou para os níveis normais. Como resultado, o nosso aeroporto pode possivelmente ser um local mais perigoso hoje do que poderia ter sido, visto que o sistema de aprendizagem está incapacitado. Isto é apenas um exemplo de um dilema geral para a segurança : é sobre a culpa ou punição, ou é sobre a aprendizagem de como fazer melhor. Não podemos ter ambos. A aprendizagem enquadra-se com a autoregulação e a punição com os mal intencionados e voltamos à questão de como categorizar empresas e indústrias para estas caixas contrastantes.

Tal sistema de acusação também não se tem provado como capaz de lidar com a responsabilidade difusa, que é tão comum em acidentes em sistemas complexos, bem defendidos, onde acidentes emergem da coincidência de muitas decisões pequenas, na qual cada uma é razoavelmente defendida individualmente. Nestes casos não há fogo à vista, no máximo podem existir espalhados uns grãos de pólvora escondidos em cantos obscuros. Precisamos de estudos mais explícitos de tais casos, de todos os ângulos, de modo a ver como estes diferentes teatros de discussão - prevenção, compensação, punição e reabilitação de vítimas e dos seus entes queridos - podem ser melhor reconciliados.

73 Em ambas estas áreas de conflito, o papel da ciência de segurança tem que ser, no meu ponto de vista, de clarificar os argumentos e fazer pesquisa para testá-los. Quais são os custos do aumento de segurança, não apenas em termos do dinheiro mas também da perda de outros objectivos do sistema? Qual é o efeito da punição depois de acidente naqueles que estão com ele relacionados, tanto vítimas como perpetradores e naqueles envolvidos em potenciais acidentes futuros do mesmo género ? Que mecanismos podem ser encontrados para conciliar nas mentes das vítimas o desejo de ver a punição e a necessidade de fazer melhorias e de aprender? Como é que a conceptualização de acidentes e os seus factores causais nas mentes de advogados e a prática da responsabilidade, seguro e compensação sobrepõem ou fazem conflito com os insights da ciência da segurança e as necessidades para a prevenção?

74 Se tivermos melhores insights então podemos ajudar os praticantes a melhor decidir, quando se manterem firmes e defenderem as regras de segurança existentes ou propostas, apesar dos seus efeitos prejudiciais noutros fins do sistema, e quando se deve ser flexível e deixar os limites das noções do envelope de segurança serem marginalmente excedidas.

\section{Avaliação}

75 O meu pedido final para o futuro retorna à esfera da ciência e da publicação. É um pedido para a avaliação da eficácia de todas as medidas de controlo do risco que tomámos, desde o design de hardware técnico, através de programas de influência de formação e comportamento para os sistemas de gestão da segurança e os seus componentes, cultura de segurança e textos regulatórios e esforços de aplicação. É um pré-requisito para dar um maior peso à segurança vs. outros resultados da regulação, 
para os quais pedi na última secção. Dos 7375 artigos nas revistas que estudei, apenas 21 fizeram menção específica nos seus títulos que eram sobre tal tipo de avaliação. Sem ter lido todos os abstracts, é difícil dizer quantos mais realmente continham avaliação que iria de encontro com critérios científicos razoáveis, mas a revisão americana de intervenções de gestão da segurança mencionada anteriormente, encontrarou apenas 13 que faziam isto. Se tomarmos isto como uma percentagem dos 182 artigos publicados que eu contei sobre este tópico, é menos de $10 \%$. Isto demonstra que a minha própria experiência em rever a literatura da formação em segurança em 1984, ainda permanece. Podendo considerar o facto de que a avaliação noutras áreas de pesquisa é mais fácil de levar a cabo, podemos estimar que os últimos 25 anos poderiam ter gerado 750 artigos com elementos da avaliação. Isto pode soar como um número elevado, mas é infinitesimal em relação com a grande largura da intervenção da segurança, e em comparação com outras áreas de pesquisa como a medicina, onde mais artigos de avaliação são publicados num ano do que nós em 35 . Os nossos estudos de campo de uma empresa de aço, regressando num período de 15 anos para reavaliar o progresso do sistema de gestão da segurança, são dos poucos estudos longitudinais na literatura (Swuste et al., 2002). Dou as boas vindas, a este respeito, à abordagem recente feita a mim como editor do Safety Science, pela Cochrane Collaboration [11], uma fundação originalmente criada para estimular e coleccionar análises topo de gama de validações de intervenções de saúde. Queriam alargar a área da Collaboration mais para a área da prevenção e controlo das lesões. As primeiras análises já foram acordadas, e será de grande valor ver quantas mais avaliações por áreas escolhidas podem ser encontradas. Receio que não serão muitas.

Porque é que estamos tão preparados na prática da segurança para aceitar e implementar por vezes medidas preventivas muito custosas, incluindo sistemas de gestão da segurança completos, sem qualquer boa base científica sobre se realmente funcionam ou não ? Parecem tão logicamente óbvias que não necessitam de validação? Não existe nenhum partido suficientemente rico para levar a cabo a pesquisa ? É levada a cabo, mas nunca chega às revistas científicas, porque é feita por empresas apenas interessadas nos resultados para elas próprias? Suponho que seja um pouco de cada uma delas. Contudo, conhecemos casos suficientes de coisas que pareciam evidentemente verdadeiras, mas que se revelou que não eram, dito isto de modo muito cauteloso. Trevor Kletz (1979), no seu discurso inaugural como professor do Chemical Safety Management em Loughborough, há quase 30 anos, discutiu uma quantidade destas quastões em relação ao processo de design. A história de casos amorosos no campo da segurança com o conceito de tendência para ter acidentes (Shaw \& Sichel, 1971), e com o triângulo de Heinrich (Hale, 2001), mostram noutras áreas como bases perfeitamente respeitáveis para a prevenção dentro de uma área bem definida, podem ser alargadas para áreas onde, no seu melhor, não são provadas, e no seu pior, não têm efeito preventivo, ou até recursos divergem de medidas mais úteis. Como candidatos para estudos de validação bem-concebidos teria na minha lista de prioridades :

- Esquemas certificatórios para os sistemas de gestão da segurança tais como o Safety Checklist for Contractors (SSVV 1997), ou auditorias para OHSAS 18001 (BSI 1999)

- Programas de formação em segurança e esquemas qualificatórios a todos os níveis desde o operador/trabalhador/condutor à gestão sénior

- Tecnologia de apoio ao condutor nos carros

- Outsourcing de empregos críticos a nível da segurança 
- Legislação baseada em fins vs regras em sectores da indústria específicos, com particular respeito aos SME

- Conselhos de profissionais da segurança

O último é inserido em parte como uma indicação de que quem pede por validação, deve também se voluntariar para o mesmo processo.

\section{Algumas reflexões sobre uma carreira na segurança} 2000 acidentes menores no shop-floor (Powell et al., 1971) e depois passei a um projecto maior, investigando centenas de erros de distribuição na área de redes de distribuição eléctrica. A oportunidade de descobrir o quão fascinantes podem ser os acidentes, devoa ao Dr. Dick Buzzard e ao Philip Powell, os designers daqueles projectos no National Institute of Industrial Psychology em Londres. O Professor Gordon Atherley escolheume para ajudar a construir o Safety \& Hygene Department, e depois o Occupational Safety and Environmental Health Department na Universidade de Aston, juntamente com o Richard Booth, que agora é Professor lá e o Dennis Else, que agora é Professor no Ballarat na Austrália, e o antigo presidente do Australian Health and Safety Comission. Devo a eles, e aos meus outros colegas de Aston agora espalhados por todo o mundo, a minha formação na multidisciplinaridade, bem como a base do meu network internacional.

Para mim, a mudança para Delft foi um salto no escuro, atraído pela oportunidade de construção de um novo grupo num país agradável, mas também fugindo da reorganização desastrosa das universidades Britânicas, iniciada por Margaret Thatcher. Caí noutro grupo de colegas fascinantes e inspiradores, e num ambiente que me deu a oportunidade de satisfazer a minha curiosidade em novas áreas da gestão da segurança e segurança de transporte, e para alargar os meus contactos Europeus pelo New Technology \& Work network e comités da International Social Security \& Health Professional Organisations. A todos os colegas no Safety Science Group, nas comitivas internacionais e Holandesas que tenho tido a honra de liderar ou de ser um membro, notavelmente na NVVK, Arboraad, SWOV e NNI, os meus agradecimentos por me terem providenciado desafios constantes, tornando-me num workaholic, mas acima de tudo por terem tornado a vida divertida. Não posso nomear todos os meus colegas, mas quero dar particular atenção aos professores em regime part-time que têm apoiado o Safety Science Group tão veementemente. Jan de Kroes, um dos mais importantes pais fundadores e ainda um activista para a segurança dos transportes; Bas de Mol, um fundador da atenção à segurança na medicina e agora a liderar trabalhos nessa área a partir do TU Eindhoven, depois de Delft ter decidido para nós que a segurança na medicina não era o negócio central ; Ben Ale, o meu digno sucessor, que trouxe a gestão desastrosa para a nossa órbita, e Ferdinand Mertens, que alargou a nossa cobertura para a regulação e a aplicação.

81 A minha carreira na segurança é caracterizada por ter questionado o que pensava serem perguntas simples, tais como: o que é esperado dos inspectores das fábricas? Como reagem os indivíduos quando são confrontados com o perigo? A formação em 
segurança realmente funciona? Como é que os designers tomam em atenção a segurança ? O que é uma boa regra de segurança ? E muitas mais. Em cada caso pensei que poderia ter passado um par de horas com um expert que me diria tudo o que quereria saber para ser capaz de avançar com o trabalho real de pôr as respostas em prática. Em cada caso reparei que não havia algum expert que me pudesse dizer. Como resultado normalmente acabava por fazer um mínimo de cinco anos de trabalho para tentar encontrar uma resposta que me satisfizesse, pelo menos como uma primeira aproximação. De cada vez estas questões levaram-me a novas áreas e podia ter a diversão de jogar do exterior perguntando questões ingénuas, óbvias, que ninguém se atreve a perguntar. Algumas vezes dão as respostas mais reveladoras. Pode-se dizer que tenho-me tornado um expert, sendo um não expert. Pensando nisso, talvez essa não seja uma má definição de um profissional de segurança. Nesse processo tenho subido nos níveis do sistema hierárquico. Comecei como biólogo virado psicólogo experimental ; para o comportamento individual no controlo do perigo na gestão da segurança e depois interessei-me pela regulação da segurança. Acima do nível do governo e da sociedade, no sistema hierárquico, apenas existe o transcendental. As minhas referências espalhadas neste discurso aos paralelos entre a segurança, a percepção do risco e as crenças religiosas podem indicar os meus primeiros passos nessa estrada, para o encontro final com o criador.

Permitam-me, no fim desta palestra, retornar novamente ao plano TU Delft "Roads to innovation". Fiquei encantado ao ver na p. 29 que a universidade quer manter o contacto com o seu pessoal emérito. Ficarei contente por manter esse contacto, que espero que seja de alguns anos de exploração produtiva mútua. Ainda existem livros e artigos para escrever, alunos de doutoramento para supervisionar e mais algumas questões ingénuas a serem respondidas. Mas a preocupação de manter tudo isto unido e desenvolvê-lo mais, deixo, de modo muito feliz, ao meu digno sucessor, Ben Ale, para o qual as minhas últimas palavras de agradecimento se dirigem, por ter retirado as preocupações de gestão dos meus ombros. Os nossos nomes têm causado confusão desde que vim para os Países Baixos, desse modo talvez ninguém repare que fizemos a troca.

\section{BIBLIOGRAFIA}

Bellamy L.J., Ale B.J.M., Geyer, T.A.W., Goossens, L.H.J., Hale A.R., Oh J.I.H., Mud, M., Bloemhoff, A., Papazoglou I.A., \& Whiston J.Y. 2006. Storybuilder : a tool for the analysis of accident reports. Reliability Engineering \& System Safety (in press).

Bloemhoff A., 2006. Search for exposure data. Paper to the 3rd International Conference on Working on Safety, Netherlands.

Bollmann U. 2006. ENETOSH European network education and training in occupational safety and health. Paper to the 3rd International Conference on Working on Safety, Netherlands. 
Bourrier M. 1998. Elements for designing a self-correcting organisation : examples from nuclear plants. In Hale A.R. \& Baram M. Safety management : the challenge of change. Pergamon. Oxford.

British Standards Institution. 1999. OHSAS 18001 :1999. Occupational health and safety management systems. Specification. London. BSI.

de Bruijne, M.L.C. 2006. Networked reliability : institutional fragmentation and the reliability of service provision in critical infrastructures. Doctoral thesis. Delft University of Tehcnology

Butter, R., Wiersma, J.W.F. 2002. Situation awareness in maritime traffic control : a comparison of two methods. In : D. de Waard (ed.) ; Human Factors in Transportation, Communication, Health, and the Workplace. Shaker Publishing BV, Nederland, , p. 377-385

Carson W.G. 1979. White collar crime and the enforcement of factory legislation. British Journal of Criminology 10 383-398.

Corrigan, S. 2002 Comparative analysis of safety management systems and safety culture in aircraft maintenance. PhD Thesis. Trinity College, Dublin

Cownie, A.R. \& Calderwood, J.H. 1966. Feedback in accident control. Operational Research Quarterly 17, 253-262 \& 310-314

Goossens L.H.J., Cooke R.M., Hale A.R. and Rodic-Wiersma, Lj. 2006. Fifteen years of expert judgement at the TU Delft. Paper to the 3rd International Conference on Working on Safety. Netherlands

Guldenmund, F., 2000. The nature of safety culture : a review of theory and research. Safety Science 34. (1-3) 215-257.

Guldenmund, F., Hale, A.R., Goossens, L.H.J. Betten, J. \& Duijm, N.J. 2005. The Development of an Audit Technique to Assess the Quality of Safety Barrier Management. J. Hazardous Materials 130 (3) 234-241

Hale, A.R. 1978. The role of HM Inspectors of Factories with particular reference to their training. PhD Thesis. University of Aston in Birmingham.

Hale A.R. 1984. Is safety training worthwhile? Journal of Occupational Accidents v6 (1) pp17-33.

Hale A.R. 2001. Conditions of occurrence of major and minor accidents. Journal of the Institution of Occupational Safety \& Health. 5 (1) 721.

Hale. A.R. 2003. Safety Management in Production. Human Factors \& Ergonomics in Manufacturing. 13 (3) 185-202.

Hale, AR 2003. SAMRAIL (Safety Management in Railways) : Safety culture in nuclear and process control WP2.1.9. Madrid : TIFSA, $32 \mathrm{pp}$.

Hale, A.R., Ale, B.J.M., Goossens, L.H.J., Bellamy, L.B., Mud M.L., Roelen, A., Baksteen, H., Post, J, Papazoglou I.A., Bloemhoff, A \& Oh, J.I.H. 2006. Modelling accidents for prioritising prevention. In Stamatelatos M.G. \& Blackman H.S. Proceedings of the 8th International Congress on Probabilistic Safety Assessment \& Management. ASME Press.

Hale, A., Glendon, A., 1987. Individual behaviour in the control of danger. Industrial safety series vol 2. Elsevier, Amsterdam

Hale A.R. \& Hale M. A review of the industrial accident research literature. 1972. Research paper for the Robens Committee on Safety \& Health at Work. National Institute of Industrial Psychology. HMSO London 
Hale A.R., Heijer T. \& Koornneef F. 2003. Management of Safety Rules : the case of railways. Safety Science Monitor v7 (1). http://www.ipso. asn.au/vol7/vol7idx.htm

Hale A.R. \& Hovden J. 1998. Management and culture : the third age of safety. In A-M Feyer \& A Williamson (eds.) Occupational Injury : risk, prevention and intervention. Taylor \& Francis. London pp 129-166. Hale A.R., Kirwan B. \& Guldenmund F. 1999. Capturing the river : multilevel modelling of safety management. In Misumi J, Wilpert B. \& Miller R. (Eds.) Nuclear safety : a human factors perspective. London. Taylor \& Francis.

Hale A.R. \& de Kroes J. 1997. System in Safety : 10 years of the chair in Safety Science at the Delft University of Technology. Safety Science 26 (1-2) pp. 3-19.

Hale, A.R., Paques-Koster, M. en Vergouw, E.G.M. 1989. Veiligheidskunde, part noch deel. Aandacht voor arbeidsveiligheid in hoger technisch onderwijs. (Safety science, neither hide nor hair : attention to occupational safety in higher technical education) Directoraat-Generaal van de Arbeid. Rapport S 56, + Bijlage S56-1. Voorburg, Ministerie van Sociale Zaken en Werkgelegenheid Hämäläinen P. Takala J. Saarela K. (2006). Global estimates of occupational accidents. Safety Science $44: 137-156$

Houtenbos, M, Hagenzieker, M, Wieringa, PA, \& Hale, AR . 2004 . Modelling interaction behaviour. In de Waard, D. Brookhuis K.A. \& Weikert C.M. (Eds.), Human Factors in Design, Analog integrated circuits and signal processing (pp. 35-47). Maastricht : Shaker Publishing

ISSA. 1991. Proposal to the Commission of the European communities for a draft directive on Education and Training in the prevention of Occupational Risks. International Social Security Association Section on Education \& Training. Paris CRAMIF.

Jagtman H.M. 2004. Road Safety by Design. Doctoral thesis Delft University of Technology Delft : Eburon Publishers.

$\mathrm{K}+\mathrm{V}$ 2005. Final Report Schiphol Safety Investigation 2005. Arnhem K+V.

Kirwan B., Hale A.R., \& Hopkins A. 2002. Changing regulations : controlling risks in society. Oxford. Pergamon.

Kletz T.A. 1979. Industrial safety : shaking the foundations. Inaugural lecture. Loughborough University of Technology.

Larsen, LD, Petersen, K, Hale, AR , Heijer, H, Parker, D, \& Lawrie, D. 2004. A Framework for Safety Rule Management. Contract no : GMA2/2001/52053. Lyngby : Danish Traffic Institute.

Mertens F.J.H. 2006. Toezicht in een polycentrische samenleving. (Regulation in a polycentric society) Inaugural lecture. TU Delft 26 April

Pietersen C.M., Hale A.R., Heming B.H.J., v.d. Broek B., Mol W.E. 1996. Evaluatieonderzoek periodieke gebruikskeuringen van arbeidsmiddelen . (Evaluation research of the periodic certification of work equipment). AEA Technology. Den Haag.

Powell P.I., Hale M., Martin J. \& Simon M. 1971. 2000 accidents : a shop floor study of their causes. Report 21. National Institute of Industrial Psychology. London.

Rasmussen J. 1997. Risk management in a dynamic society : a modelling problem. Safety Science $27(2 / 3) 183-213$.

Robson, L.S., Clarke, J.A.., Cullen, K., Bielecky, A., Severin, C., Bigelow, P., Irvin, E. \& Culyer, A.J. The effectiveness of occupational health and safety management system interventions : a systematic review. Safety Science (in press) 
Robens. Lord. 1972. Safety and health at work : report of the committee. HMSO. London.

Rundmo T \& Hale A.R. 2003. Managers' attitudes towards safety and accident prevention. Safety Science 41 (7) 427-443

Shaw, L.S. \& Sichel, H.S. 1971. Accident Proneness. Pergamon. Oxford Short Time Committee of Birstall (1833) Address to the Friends of Justice, quoted in Thomas M.W. (1948) The Early Factory Legislation. Leigh on Sea. Thomas Bank Publishing

SSVV. 1997. VCA : Safety checklist for contractors. Leidschendam. SSVV. Swuste, P., 1996. Occupational hazards, risks and solutions. Doctoral Thesis, Delft University of Technology, Delft, the Netherlands.

Swuste, P., F. Guldenmund, A. Hale, P. Heimplaetzer, B. Heming en P. Oortman Gerlings, 1994. Evaluatie van een gedecentraliseerde veiligheidszorgsysteem in een geïntegreerde staalfabriek (Evaluation of a decentralised safety management system in an integrated steel works). Research report. Safety Science group. Delft University of Technology, Netherlands.

Swuste, P, Hale, A.R. \& Guldenmund, F., 2002. Change in a steel works : learning from failures and partial successes. In Wilpert B. \& Fahlbruch B. (Eds) System safety : challenges and pitfalls of intervention. Pergamon. Oxford.

Tingvall, C. 2002. Vision Zero the death of cost-benefit analysis. Keynote presentation. Working on Safety Conference. Elsinore, Denmark.

VACS 2005. Advice on the Safety Investigation Schiphol 2005. http:// demo73.auto-interactive.nl/ imgbase/portal_65/Advice\%20Safety\%2 OInvestigation \%20Schiphol \%202005.pdf

Venema, A. , Bloemhoff, A., Ybema, J.F., Stam, C.A., 2006. Monitoring occupational accidents in the Netherlands : Does it work for prevention? Paper to the 3rd International Conference on Working on Safety, Netherlands.

Westrum R. 1991. Cultures with requisite imagination. In : Wise J., Stager P. \& Hopkin J. (Eds.) Verification and validation in complex manmachine systems. Springer. New York.

Wilde G.J.S. 1994. Target Risk. PDE Publications Toronto

\section{NOTAS}

1. Arbo, abreviatura de arbeidsomstandigheden, a palavra Holandesa para condições de trabalho.

2. Duas outras revistas relevantes não estavam disponíveis neste modo - Risk Analysis (1980), International Journal of Injury Control \& Safety Promotion, previamente International Journal of Consumer \& Product Safety (1994) e não são incluídos, uma limitação a ser tida em conta ao interpretar as minhas conclusões.

3. A revista foi publicada com o título 'Reliability Engineering' em 19 volumes anteriores a esta data, mas estes não foram analisados.

4. Os meus devidos agradecimentos a Frits Claus, agora o Inspectie Werk \& Inkomen do Dutch Ministry of Social Affairs and Employment, que utilizou a sua extensa rede de contactos para me tornar disponíveis os números Britânicos e Holandeses.

5. Uma vez que a principal revista de segurança do consumidor e a principal revista de risco da sociedade não puderam ser incluídas neste estudo - ver rodapé 2 - a imagem é um pouco distorcida, mas mesmo com a análise dessas revistas a imagem geral não mudaria significativamente. 
6. Números para 1992 do Central Bureau of Statistics, a última data em que estes números comparativos estiveram disponíveis.

7. Algumas decisões relativamente arbitrárias foram necessárias na alocação dos artigos. Por exemplo, os modelos de efeito de acidentes foram alocadas para o nível técnico, assim como a maior parte dos artigos que se relacionam com a modelação da dispersão química; a análise do risco também foi alocada aqui, visto que lida em grande parte com falhas técnicas - mas os artigos da análise da fiabilidade humana foram codificados como factores humanos.

8. Num trabalho recente para o Dutch Social Affairs Ministry, 9000 destas 'histórias terríveis' de sérios acidentes registados, foram codificadas em detalhe recorrendo a novo software desenvolvido por Linda Bellamy et al. (2006)

9. Este artigo, apesar de longo, é demasiado curto para mencionar todo o pessoal e estudantes de doutoramento e os seus projectos, que têm alimentado este programa de pesquisa e irão continuar a fazê-lo. O programa Risk Centre trabalha actualmente com cerca de 30 doutorados internos e externos.

10. Isto não é nenhum ponto de vista novo. Autores tal como Carson (1979) tinham já salientado esta divisão na regulação da segurança há muitas décadas.

11. Endereço de Internet www.cochrane.org

\section{AUTOR}

\section{ANDREW HALE}

Delft University of Technology Portbus, 50152600 GA Delft Netherlands

a.r.hale@tudelft.nl 